\title{
Thrust and bending moment of rigid piles subjected to moving soil
}

\author{
Wei Dong Guo and H.Y. Qin
}

\begin{abstract}
An experimental apparatus was developed to investigate the behaviour of vertically loaded free-head piles in sand undergoing lateral soil movement $\left(w_{\mathrm{f}}\right)$. A large number of tests have been conducted to date. Presented here are 14 typical model pile tests concerning two diameters, two vertical pile loading levels, and varying sliding depths with the movement $w_{\mathrm{f}}$ driven by a triangular loading block. Results are provided for driving force as well as for induced shear force $(T)$, bending moment $(M)$, and deflection $(y)$ along the piles with $w_{\mathrm{f}} /$ normalized sliding depth. The tests enable simple expressions to be proposed, drawn from the theory for a laterally loaded pile. The new expressions well capture the evolution of $M, T$, and $y$ with soil movement observed in current model tests, and the three to five times difference in maximum bending moment $\left(M_{\max }\right)$ from the two modes of loading. They further offer a good estimate of $M_{\max }$ for eight in situ pile tests and one centrifuge test pile. The study quantifies the sliding resistance offered by a pile for the given $w_{\mathrm{f}}$ profiles, pile location (relative to the boundary), and vertical load. It establishes the linear correlation between the maximum thrust (resistance $T$ ) and $M_{\max }$, regardless of the magnitudes of $w_{\mathrm{f}}$.
\end{abstract}

Key words: ground improvement, model tests, piles, slopes, soil-structure interaction, theoretical analysis.

Résumé : Un appareil expérimental a été développé dans le but d'examiner le comportement de pieux a tête libre chargés verticalement dans du sable qui se déplace latéralement $\left(w_{\mathrm{f}}\right)$. De nombreux essais ont été effectués jusqu'à maintenant. Dans cet article, 14 essais modèles typiques couvrant deux diamètres de pieux, deux niveaux de chargement vertical et des profondeurs de glissement variables, avec le mouvement $w_{\mathrm{f}}$ induit par un bloc de chargement triangulaire, sont présentés. Les résultats informent sur la force motrice, la force de cisaillement induite $(T)$, le moment de torsion $(M)$ et la déflection ( $y$ ) le long des pieux avec $w_{\mathrm{f}} /$ profondeur de glissement normalisée. Les essais permettent de proposer des expressions simples avec une emphase sur la théorie pour les pieux chargés latéralement. Les nouvelles expressions représentent l'évolution de $M, T$ et $y$ selon les mouvements du sol observés dans les essais, ainsi que la différence d'un facteur trois à cinq fois entre les moments de torsion maximaux $\left(M_{\max }\right)$ pour deux modes de chargement. De plus, ces expressions offrent une bonne estimation de $M_{\max }$ pour huit essais de pieux in situ et un essai centrifuge. L'étude quantifie la résistance au glissement exercée par un pieu pour des profils donnés de $w_{\mathrm{f}}$, la position du pieu (par rapport à la frontière) et le chargement vertical. Une corrélation linéaire est établie entre la poussée maximale (résistance $T$ ) et $M_{\max }$, et ce peu importe la magnitude de $w_{\mathrm{f}}$.

Mots-clés : amélioration du sol, essais modèles, pieux, pentes, interaction sol-structure, analyse théorique.

[Traduit par la Rédaction]

\section{Introduction}

The study of active piles subjected to combined lateral and vertical loads has attracted significant research effort (Meyerhof et al. 1981, 1983; Anagnostopoulos and Georgiadis 1993; Aubeny et al. 2003; Karthigeyan et al. 2007). However, there is limited information available on the study of (passive) pile response when subjected to lateral soil movement and vertical loading (Knappett and Madabhushi 2009). It is not clear how bending moment is related to maximum sliding force (lateral thrust) developed in a passive pile; in particular, once coupled with vertical loads and various soil movement profiles. The correlation needs to be established to facilitate design and inspection of piles used

Received 4 December 2008. Accepted 30 July 2009. Published on the NRC Research Press Web site at cgj.nrc.ca on 2 February 2010.

W.D. Guo ${ }^{1}$ and H.Y. Qin. School of Engineering, Griffith University, Gold Coast Campus, QLD 4222, Australia.

${ }^{1}$ Corresponding author (e-mail: w.guo@Griffith.edu.au). to stabilize slopes and to support bridge abutments and foundations of tall buildings. Studies to date have principally been based on centrifuge tests (Stewart et al. 1994; Bransby and Springman 1997; Leung et al. 2000), laboratory model tests (Poulos et al. 1995; Pan et al. 2002; Guo and Ghee 2004), and theoretical and numerical analyses (Ito and Matsui 1975; Viggiani 1981; Poulos 1995; Guo 2003). The results are useful in one way or another. Nevertheless, it is unfortunate that the correlation between the moment and the lateral thrust (i.e., shear force in a pile) in the majority of model pile tests was not provided. The force is indeed required to evaluate maximum bending moment (Poulos 1995) in design piles in the aforementioned situation.

Limit equilibrium solutions have been derived for piles in a two-layered cohesive soil (Viggiani 1981; Chmoulian 2004). They allow the maximum bending moment to be correlated to lateral thrust by stipulating $(i)$ a fixed sliding depth and (ii) a uniform soil movement profile (without axial load on the pile head). The solutions are popularly used for passive piles. Likewise, methods based on the $p-y$ curve are widely adopted in practice. However, recent study shows 
that the $p-y$ method significantly overestimated pile deflection and bending moment; therefore; further research is warranted (Frank and Pouget 2008). The response of in situ slope stabilizing piles has been recorded by several researchers (Esu and D'Elia 1974; Fukuoka 1977; Carrubba et al. 1989; Kalteziotis et al. 1993; Smethurst and Powrie 2007; Frank and Pouget 2008). Among others, elastic solutions (Fukuoka 1977; Cai and Ugai 2003) and elastic-plastic solutions $^{2}$ were developed. The former compares well with measured pile response at the reported stress states. The elastic-plastic solutions can capture well the nonlinear response of passive piles at any soil movement. Nevertheless, the effect of soil movement profiles on the response, coupled with an axial load and in a pre-failure state, has yet to be clarified. This can be examined through model pile tests. Above all, a simple correlation between lateral thrust and maximum bending moment is needed to facilitate practical design.

A small-scale experiment can bring about valuable insight into the pile-soil interaction mechanism. It can clarify and quantify key parameters (Abdoun et al. 2003). To examine the response of passive piles, Guo and Ghee (2004) developed a new experimental apparatus. Extensive tests have been conducted to date on piles in sand. Some results were published previously (Guo and Ghee 2005; Guo et al. 2006). This paper presents 14 typical results from testing under an inverse triangular loading block, which were deduced from test piles of two diameters and subjected to two axial load levels. They are analyzed to

- establish the relationship between maximum bending moment and lateral sliding thrust; and

- simulate the evolution of the moment and the sliding thrust with moving soil.

The test results are presented in the form of profiles of bending moment, shear force, and deflection along the pile versus frame movement or normalized sliding depth. The measured correlation between maximum bending moment and lateral thrust and between the thrust and soil movement are provided. These correlations allow newly developed expressions to be validated with respect to the impact of subgrade modulus, vertical load, two different (translational or rotational) loading methods, and effective soil movement. The established correlations are further compared with measured data of eight in situ test piles and one centrifuge test pile.

\section{Apparatus and test procedures}

\section{Shear box and loading system}

Figure 1 shows an overview of the experimental apparatus developed in the current study. It is mainly made up of a shear box, a loading system, and a data acquisition system. The shear box measures $1 \mathrm{~m}$ both in length and width. The upper section of the shear box consists of $25 \mathrm{~mm}$ deep square laminar steel frames. The frames, which are allowed to slide, contain the "moving layer of soil" of thickness $L_{\mathrm{m}}$. The lower section of the shear box comprises a $400 \mathrm{~mm}$ height fixed timber box and the desired number of laminar steel frames that are fixed after placement, so that a stable
Fig. 1. Schematic diagram of shear box: (a) elevation view; $(b)$ initial plan view A-A. LVDT, linear variable displacement transducer.

(a)

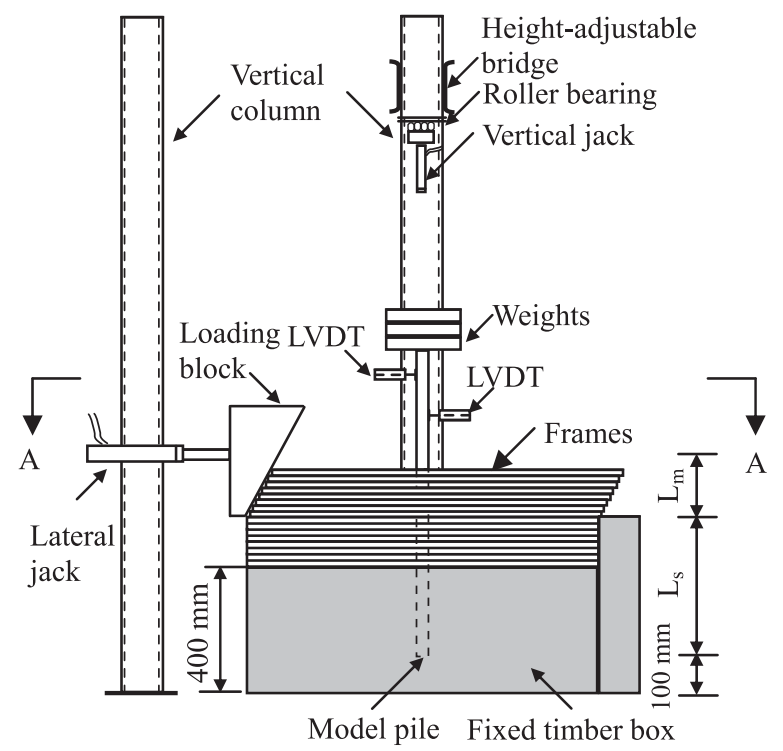

(b)

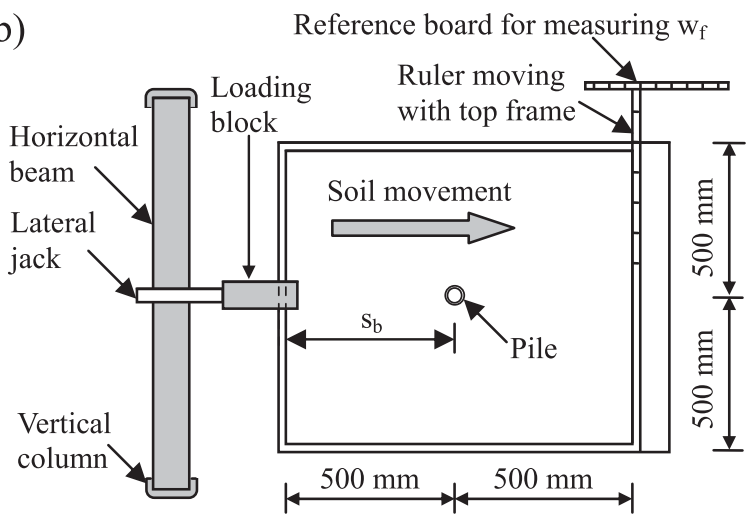

layer of soil of thickness $L_{\mathrm{s}}(\geq 400 \mathrm{~mm})$ can be guaranteed. By changing the number of movable frames in the upper section, the thicknesses of the stable and moving layers are varied accordingly. Note that the $L_{\mathrm{m}}$ and $L_{\mathrm{s}}$ are defined at the loading location and that they vary across the shear box. The actual sliding depth $L_{\mathrm{m}}$ around a test pile is unknown, but it would not affect the conclusions being drawn in this paper.

The loading system encompasses a loading block that is placed on the upper movable laminar frames and some weights on top of the test pile. The loading block is made of different shapes to generate various soil movement profiles. The triangular loading block employed here has a (loading) angle of $16.7^{\circ}$ (see Fig. 2). A translational frame movement of $w_{\mathrm{f}}$ will induce an increasing sliding depth of $3.33 w_{\mathrm{f}}$ (at the loading location) until a pre-specified final depth of $L_{\mathrm{m}}$. Thereafter, additional frame movement will be uniform over the depth $L_{\mathrm{m}}$, resulting in an overall trapezoi-

\footnotetext{
${ }^{2}$ Guo, W.D. Nonlinear response of slope stabilising piles (unpublished).
} 
Fig. 2. Schematic test of a pile subjected to triangular loading block: $(a)$ instrumented model pile; $(b)$ schematic diagram of testing. $d$, outer diameter; TD and TS, test designations (refer to text). All dimensions in millimetres.

(a)

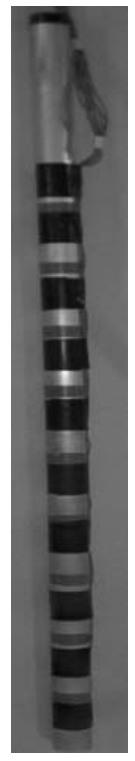

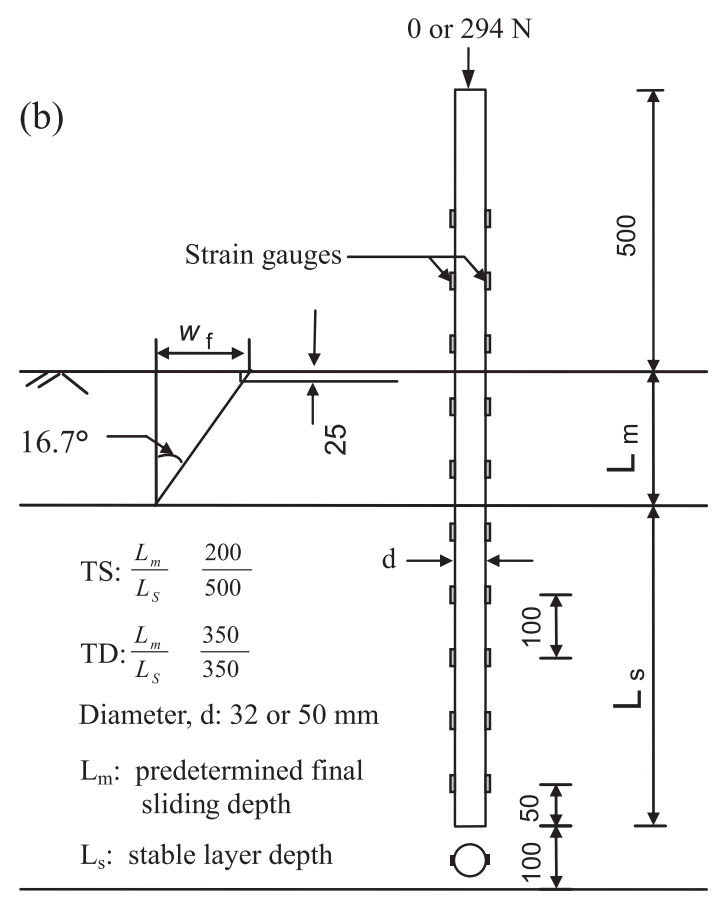

dal soil movement profile. A hydraulic jack is used to drive the loading block. The jack stroke permits a lateral frame movement $w_{\mathrm{f}}$ of up to $150 \mathrm{~mm}$. Response of the pile is monitored via strain gauges distributed along the piles (see Fig. 2a) and via two linear variable displacement transducers (LVDTs) above the model ground (Fig. 1). The test readings are recorded and processed via a data acquisition system and a computer, which are transferred into "measured" pile response using a purposely designed program discussed later.

\section{Sample preparation and sand properties}

Medium oven-dried quartz sand was utilized in this study. Figure 3 shows its particle-size distribution, which has an effective grain size $D_{10}=0.12 \mathrm{~mm}$, a uniformity coefficient $C_{\mathrm{u}}=2.92$, and a coefficient of curvature $C_{\mathrm{c}}=1.15$. The sand was rained into the shear box through a rainer hanging over the box. The falling height, chosen as $600 \mathrm{~mm}$ in this study, was selected to generate a uniform and desired density. This is intended to offer a relative density of $89 \%$ and a unit weight of $16.27 \mathrm{kN} / \mathrm{m}^{3}$ (see Fig. 4). The angle of internal friction of the sand is $38^{\circ}$ as evaluated from direct shear tests.

\section{Model pile}

The aluminium pipe piles tested each had a length of $1200 \mathrm{~mm}$ (see Fig. 2a). They were made of two configurations: one had an outer diameter $(d)$ of $32 \mathrm{~mm}$, a wall thickness $(t)$ of $1.5 \mathrm{~mm}$, and a flexural stiffness $\left(E_{\mathrm{p}} I_{\mathrm{p}}\right)$ of $1.17 \mathrm{kN} \cdot \mathrm{m}^{2}$; the other had $d=50 \mathrm{~mm}, t=2 \mathrm{~mm}$, and $E_{\mathrm{p}} I_{\mathrm{p}}=6.09 \mathrm{kN} \cdot \mathrm{m}^{2}$. Ten levels of strain gauges, placed on the pile surface at intervals of $100 \mathrm{~mm}$, were calibrated prior to the tests. This was done by applying a transverse load in the middle of the pile clamped at both ends. Each gauge reading measured under various loads was then compared with the theoretically calculated strain. A calibration factor was thus obtained for each gauge, which permits the gauge readings to be converted to actual strains. During the pile test, the strain gauges were protected from damage by covering them with $1 \mathrm{~mm}$ of epoxy and wrapping them with tapes.

\section{Test programme}

A series of tests were conducted using the triangular loading block. Fourteen typical tests are presented here and summarized in Table 1. Each test is denoted by two letters and two numbers, e.g., TS32-0 and TD32-294: (i) the triangular loading block is signified as "T"; (ii) the " $\mathrm{S}$ " and " $\mathrm{D}$ " refer to a pre-selected sliding depth $\left(L_{\mathrm{m}}\right)$ of 200 and $350 \mathrm{~mm}$, respectively; (iii) the "32" indicates $32 \mathrm{~mm}$ in diameter, and (iv) the " 0 " or "294" represents without or with an axial load of $294 \mathrm{~N}$, respectively. Three types of tests - "pile location", "standard", and "varying sliding depth" — are reported here:

- Pile location tests were carried out to investigate the impact of relative distance between the loading block and pile location, etc.

- Standard tests were performed to determine the response to the two final pre-selected sliding depths of 200 and $350 \mathrm{~mm}$.

- Varying sliding depth tests were done to highlight bending moment increases owing to additional movement beyond the triangular profile.

First, for each test, the sample model ground was prepared in the way described previously to a depth of $800 \mathrm{~mm}$. Second, the instrumented pile was jacked in continuously to a depth of $700 \mathrm{~mm}$ below the surface, while the (driving) resistance was monitored. Third, an axial load 
Fig. 3. Particle-size distribution of sand used.

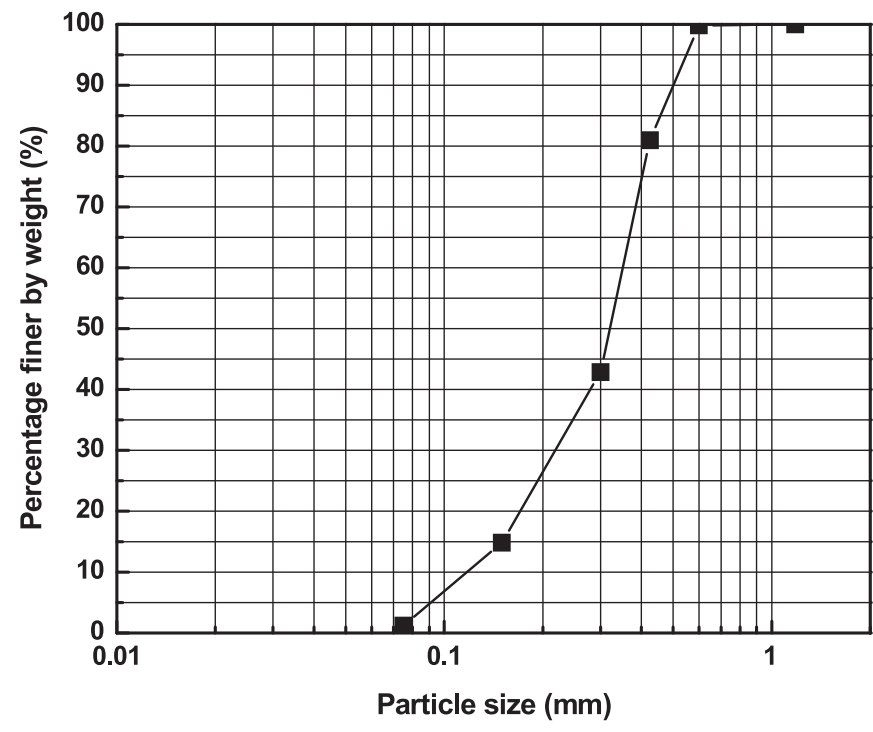

Fig. 4. Relationship between falling height and sand density.

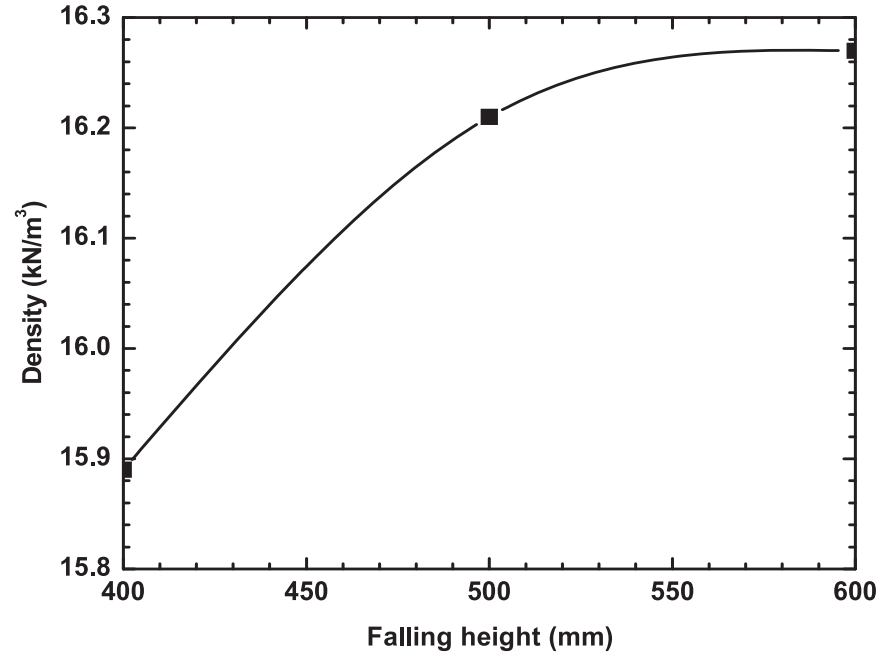

was applied on the pile head using a number of weights (to simulate a free-head pile condition) that were secured (by using a sling) at $500 \mathrm{~mm}$ above the soil surface. Fourth, the lateral force was applied via the triangular block on the movable frames to enforce translational soil movement towards the pile. And finally, the sand was emptied from the shear box after each test.

During the passive loading, the gauge readings, the linear variable displacement transducer (LVDT) readings, and the lateral force on the frames were generally taken at every $10 \mathrm{~mm}$ movement of the top laminar steel frame (e.g., frame movement, $w_{\mathrm{f}}$ ) to $\sim 150 \mathrm{~mm}$. A number of trial tests prove the repeatability and consistency of test results presented here.

\section{Determining pile response}

A spreadsheet program using Microsoft Excel VBA was written to process and analyze the data obtained from strain gauges and LVDTs. The inclination and deflection profiles along the pile were derived, respectively, from first and second order numerical integration of the bending moment pro- file. The shear force and soil reaction profiles were deduced by using single and double numerical differentiation of the bending moment profile, respectively. With this program, typical response profiles of bending moment, shear force, soil reaction, deflection, and rotation profiles (Guo and Qin 2006) were deduced for all the tests. They allow the following response to be gained for typical frame movement $w_{\mathrm{f}}$ : maximum bending moment, $M_{\max }$; depth of the moment, $d_{\text {max }}$; maximum thrust (shear force in the pile), $T_{\max }$; and pile deflection at the groundline, $y_{\mathrm{t}}$ (see Table 1).

\section{Influence factors on test results}

The current test apparatus allows nonuniform mobilization of soil movement across the shear box. The resulting impact is revealed by the pile location tests. A pile (with $d=32 \mathrm{~mm}$ ) was installed at a distance $s_{\mathrm{b}}$ of 340, 500 or $660 \mathrm{~mm}$ from the loading jack side. For instance, a $s_{\mathrm{b}}$ of $500 \mathrm{~mm}$ is for a pile installed at the centre of the box. Driving the loading block at the pre-specified final sliding depth of $200 \mathrm{~mm}$, three tests were conducted. The $M_{\max }$ obtained is plotted against $s_{\mathrm{b}}$ in Fig. 5. It shows a reduction of $\sim 32 \mathrm{kN} \cdot \mathrm{mm}$ (at $w_{\mathrm{f}}=$ $70 \sim 80 \mathrm{~mm}$ ) in the moment as the pile was relocated from $s_{\mathrm{b}}=340$ to $500 \mathrm{~mm}$, and a reduction of $\sim 10 \mathrm{kN} \cdot \mathrm{mm}$ from $s_{\mathrm{b}}=500$ to $660 \mathrm{~mm}$. The total maximum moment was $45 \sim 50 \mathrm{kN} \cdot \mathrm{mm}$ for the pile tested at the centre of the box. All the piles reported subsequently were tested at the centre.

\section{Test results}

\section{Driving force and lateral force on frames}

The jack-in forces for six typical tests were recorded during the installation. They are plotted in Fig. 6. The figure shows a more or less linear increase in driving force with the pile penetration. At the final penetration of $700 \mathrm{~mm}$, the average total forces of the same diameter piles reach $5.4 \mathrm{kN}$ ( $d=50 \mathrm{~mm}$ piles) and $3.8 \mathrm{kN}(d=32 \mathrm{~mm}$ piles), with a variation of $\sim \pm 20 \%$. This reflects the possible variations in model ground properties, as the jack-in procedure was consistent. (Note the axial load of $294 \mathrm{~N}$ on the pile head was $7 \% \sim 9 \%$ of the final jacking resistance). The average shaft friction for the installation is estimated as $54 \mathrm{kPa}(d=$ $32 \mathrm{~mm})$ and $49.1 \mathrm{kPa}(d=50 \mathrm{~mm})$, ignoring the end resistances on the open-ended piles.

Total lateral force on the frames was recorded via the lateral jack during the tests upon each $10 \mathrm{~mm}$ frame movement $\left(w_{\mathrm{f}}\right)$. They are plotted in Fig. 7 for the six tests. Figures $8 a-$ $8 g$ provide the photos taken during the test TS50-294 for a few typical $w_{\mathrm{f}}$. Figure 7 demonstrates the following:

- In general, force linearly increases with the frame movement until it becomes constant.

- Shear modulus of the sand, $G_{\mathrm{s}}$, is deduced as $15 \sim 21 \mathrm{kPa}$ using the linear portion of each force-movement curve. For instance, with the TS test series, the maximum shear stress $\tau$ is estimated as $4.5 \sim 5.0 \mathrm{kPa}(=4.5 \sim 5.0 \mathrm{kN}$ on loading block over shear area of $1.0 \mathrm{~m}^{2}$ ). The maximum shear strain $\gamma$ is evaluated as $0.25 \sim 0.3\left(=w_{\mathrm{f}} / L_{\mathrm{m}}\right.$, with $w_{\mathrm{f}}=50 \sim 60 \mathrm{~mm}$ and $L_{\mathrm{m}}=200 \mathrm{~mm}$ ), assuming the shear force is transferred across the sliding depth $L_{\mathrm{m}}$ of $200 \mathrm{~mm}$. The ultimate shear resistance offered by the pile is $\sim 0.6 \mathrm{kN}$ (see Fig. 9), which accounts for $\sim 10 \%$ the total applied force of $5 \sim 8 \mathrm{kN}$ on the frames. The de- 
Table 1. Summary of 14 typical pile tests.

\begin{tabular}{|c|c|c|c|c|c|c|c|c|}
\hline \multirow[b]{2}{*}{ Test description } & \multirow[b]{2}{*}{$\begin{array}{l}\text { Frame movement } \\
\text { at ground } \\
\text { surface, } w_{\mathrm{f}}(\mathrm{mm})\end{array}$} & \multicolumn{2}{|c|}{$\begin{array}{l}\text { Maximum bending moment, } \\
M_{\max }(\mathrm{kN} \cdot \mathrm{mm})\end{array}$} & \multirow[b]{2}{*}{$\begin{array}{l}\text { Depth of } \\
M_{\max }, d_{\max } \\
(\mathrm{mm})\end{array}$} & \multicolumn{2}{|c|}{$\begin{array}{l}\text { Maximum shear force, } \\
T_{\max }(\mathrm{N})\end{array}$} & \multirow[b]{2}{*}{$\begin{array}{l}\text { Pile deflection } \\
\text { at groundline, } \\
y_{\mathrm{t}}(\mathrm{mm})\end{array}$} & \multirow[b]{2}{*}{$\begin{array}{l}L_{\mathrm{m}} / L_{\mathrm{s}} \\
(\mathrm{mm}) \\
\end{array}$} \\
\hline & & $\begin{array}{l}\text { Tension } \\
\text { side }\end{array}$ & $\begin{array}{l}\text { Compression } \\
\text { side }\end{array}$ & & Stable layer & $\begin{array}{l}\text { Sliding } \\
\text { layer }\end{array}$ & & \\
\hline \multicolumn{9}{|l|}{ Pile location } \\
\hline $\operatorname{TS} 32-0\left(s_{\mathrm{b}}=340\right)$ & $60 / 80$ & $63.8 / 81.0$ & - & 400 & $266.9 / 327.7$ & $266.6 / 325.8$ & $11.5 / 14.8$ & $200 / 500$ \\
\hline $\mathrm{TS} 32-0\left(s_{\mathrm{b}}=660\right)$ & $60 / 80$ & $30.0 / 40.0$ & - & 400 & $114.9 / 150.3$ & $120.4 / 153.7$ & $7.8 / 10.8$ & $200 / 500$ \\
\hline $\operatorname{TS} 32-0\left(L_{\mathrm{m}}=200\right)$ & $60 / 70$ & $39.3 / 49.7$ & $-34.2 /-45.0$ & 370 & $147.2 / 183.8$ & $159.8 / 201.1$ & $7.1 / 10.3$ & $200 / 500$ \\
\hline TS32-294 & $60 / 90$ & $29.8 / 78.6$ & $-26.8 /-76.5$ & 375 & $108.5 / 295.5$ & $98.0 / 279.9$ & $5.4 / 13.1$ & $200 / 500$ \\
\hline TS50-0 & $60 / 80$ & $45.8 / 89.2$ & $-37.9 /-80.2$ & 380 & $191.9 / 363.9$ & $180.3 / 355.7$ & $2.9 / 7.2$ & $200 / 500$ \\
\hline TS50-294 & $60 / 80$ & $58.5 / 115.6$ & $-59.2 /-120.0$ & 400 & $229.6 / 445.5$ & $241.4 / 467.5$ & $3.5 / 7.3$ & $200 / 500$ \\
\hline TD32-0 & 120 & 119.5 & -112.1 & 450 & 495.9 & 414.8 & 58.7 & $350 / 350$ \\
\hline TD32-294 & 120 & 124.6 & -117.5 & 465 & 532.4 & 463.5 & 73.8 & $350 / 350$ \\
\hline $\mathrm{T} 32-0\left(L_{\mathrm{m}}=250\right)$ & $80 / 120$ & $62.6 / 123.5$ & - & 450 & $258.1 / 509.4$ & $233.9 / 457.3$ & $22.4 / 47.7$ & $250 / 450$ \\
\hline $\mathrm{T} 32-0\left(L_{\mathrm{m}}=300\right)$ & $100 / 150$ & $115.3 / 175.0$ & - & 450 & $450.6 / 675.2$ & $399.4 / 619.6$ & $25.1 / 54.8$ & $300 / 400$ \\
\hline $\mathrm{T} 32-0\left(L_{\mathrm{m}}=350\right)$ & $120 / 150$ & $118.1 / 140.0$ & - & 475 & $471.7 / 557.3$ & $406.7 / 535.3$ & $42.2 / 73.9$ & $350 / 350$ \\
\hline
\end{tabular}

Note: Except for $L_{\mathrm{m}} / L_{\mathrm{s}}$, "/" denotes two separate measurements at the two specified values of $w_{\mathrm{f}}$.

Fig. 5. Variation of maximum bending moment, $M_{\max }$, versus distance of pile from loading side, $s_{\mathrm{b}}$.

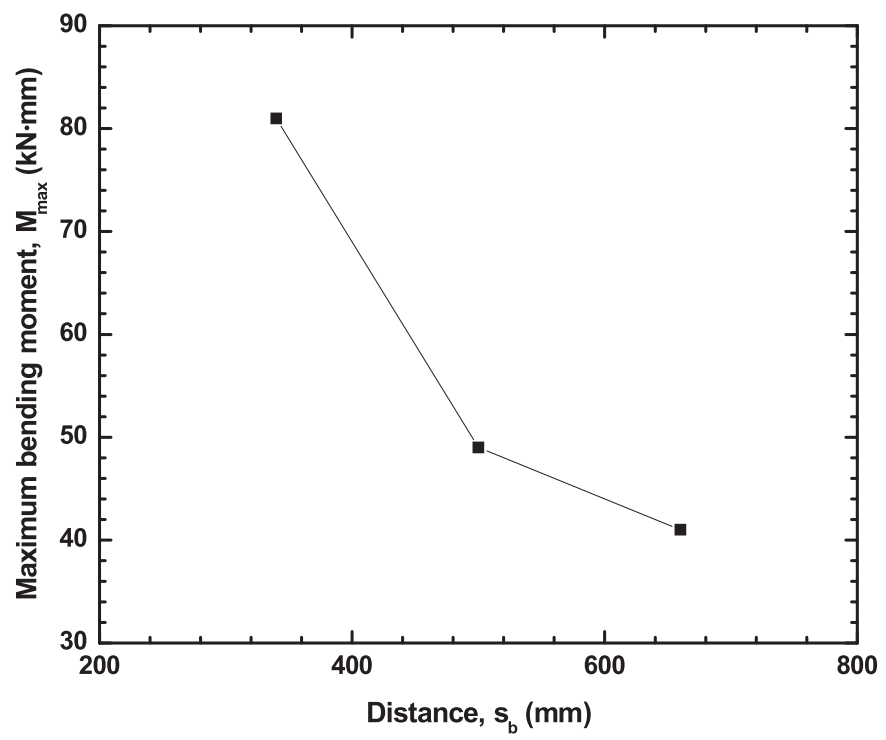

termined shear stress and modulus may thus be reduced by $\sim 10 \%$ for the tests without the pile.

- Average overburden stress, $\sigma_{\mathrm{v}}$, at the sliding depth of $200 \mathrm{~mm}$ is about $1.63 \mathrm{kPa}(=16.3 \times 0.1)$. At this low stress level, sand dialatancy is evident, which generates a number of "heaves" (see Fig. 8h).

- Lateral force attained a maximum value either around $w_{\mathrm{f}}=50 \sim 60 \mathrm{~mm}$ (TS series) or around $90 \sim 120 \mathrm{~mm}$ (TD series), and dropped slightly afterwards. The slight fluctuation in the force at large frame movements reflects stress build-up and redistribution around the pile as exhibited by the gradual formation of "heaves". The pile
Fig. 6. Jack-in resistance measured during pile installation.

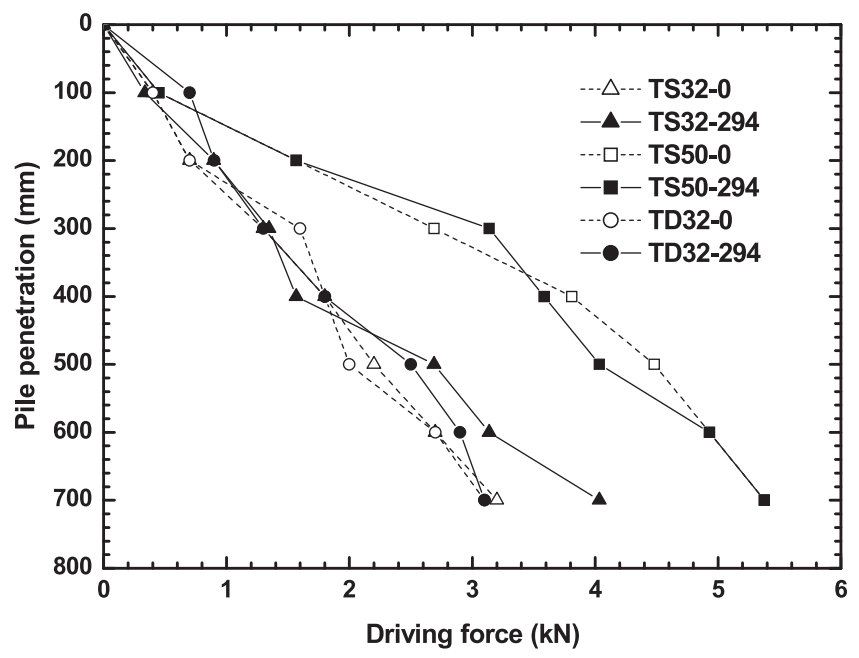

response, however, attained a maximum value at a higher $w_{\mathrm{f}}$ of either $70 \sim 90 \mathrm{~mm}$ (TS series) or $120 \mathrm{~mm}$ (TD series) shown later, indicating a difference of $\sim 30 \mathrm{~mm}$ in $w_{\mathrm{f}}$ (i.e., $w_{\mathrm{i}}$ shown later) in transferring the applied force to the pile.

Figure 8 shows the sequential frame movements in lateral and vertical dimensions as the loading block advances. Table 2 shows the typical $w_{\mathrm{f}}$ and the sliding depth induced. A sliding depth ratio $R_{\mathrm{L}}$ is defined as the ratio of thickness of moving soil $\left(L_{\mathrm{m}}\right)$ over the pile embedment length (i.e., $L=$ $\left.L_{\mathrm{m}}+L_{\mathrm{S}}\right)$. It is utilized later to quantify the impact of depth of moving layer. For instance, in the TS test series, a $w_{\mathrm{f}} \leq$ $60 \mathrm{~mm}$ would correspond to a triangular profile to a sliding depth $L_{\mathrm{m}}$ of $200 \mathrm{~mm}$, otherwise to a trapezoidal soil movement profile with a constant $R_{\mathrm{L}}=0.29$. 
Fig. 7. Total applied force on frames against frame movements.

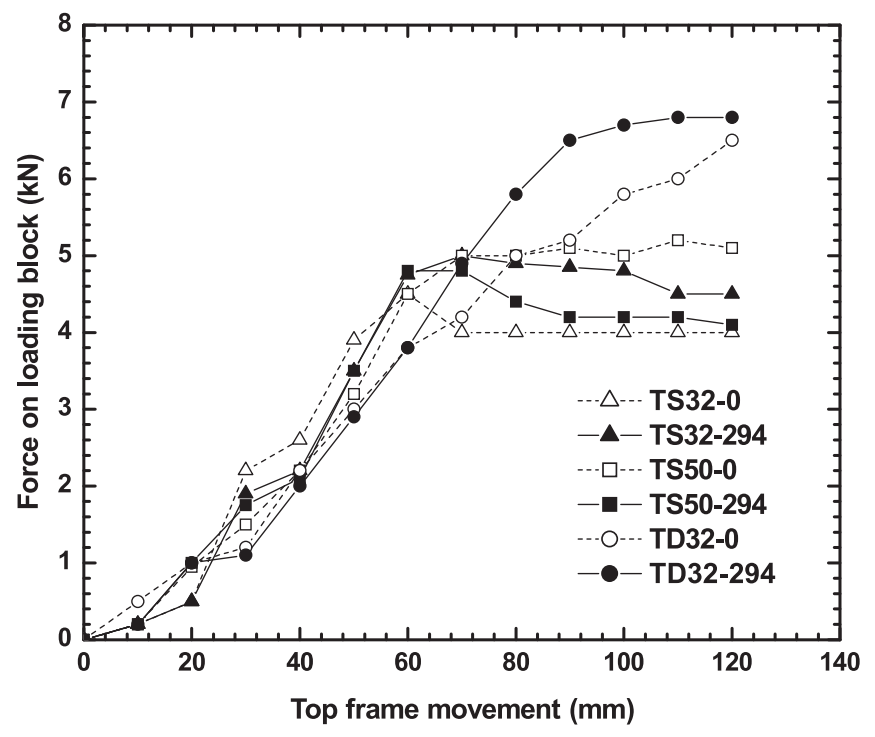

\section{Response of $M_{\max }, d_{\max }$, and $y_{\mathrm{t}} \operatorname{versus} w_{\mathrm{i}}\left(w_{\mathrm{f}}\right)$}

Figure 10 shows the profiles of bending moment, shear force, and pile deflection deduced from the test on the $32 \mathrm{~mm}$ diameter pile without axial load (TS32-0). Figure 11 provides the same profiles for the test on the pile with a load of 294 N (TS32-294). They reflect the impact of the triangular movement profile for $w_{\mathrm{f}} \leq 60 \mathrm{~mm}$ and that of the trapezoidal profile afterwards. Critical responses of maximum bending moment, $M_{\max }$, depth, $d_{\max }$, and head deflection at groundline, $y_{t}$, are obtained and highlighted below:

- At the maximum response state and without axial load (TS32-0), $M_{\max }=49.7 \mathrm{kN} \cdot \mathrm{mm}, d_{\max }=370 \mathrm{~mm}$, and $y_{\mathrm{t}}=$ $10 \mathrm{~mm}$. The pile mainly rotated (see Fig. 10) about the pile tip.

- Imposing the axial load, the $M_{\max }$ increases to $78.6 \mathrm{kN} \cdot \mathrm{mm}$ (i.e., $60 \%$ increase compared with without load) (see Fig. 11). Negative bending moment was observed around the sand surface at the initial stage with $w_{\mathrm{f}}=\sim 40 \mathrm{~mm}\left(R_{\mathrm{L}}<0.17\right)$. The pile rotated about a depth of $550 \sim 700 \mathrm{~mm}$ (pile tip level) and induced a deflection $y_{\mathrm{t}}$ of $\sim 13 \mathrm{~mm}$ (i.e., $30 \%$ increase).

The strongest response profiles are observed at $w_{\mathrm{f}}=$ $70 \sim 90 \mathrm{~mm}(d=32 \mathrm{~mm})$ for the two tested piles. They are plotted in Figs. $12 a$ and $12 b$ along with those reported previously for $d=50 \mathrm{~mm}$ (Guo and Qin 2006). The evolution of the maximum bending moment $M_{\max }$ and shear force $T_{\max }$ are furnished in Figs. $13 a$ and $13 b$ against the movement $w_{\mathrm{f}}$ (for $d=50$ and $32 \mathrm{~mm}$ ), respectively. The figures demonstrate the following:

- A small thickness of moving soil (with $R_{\mathrm{L}}<0.17$, thus $L_{\mathrm{m}}<120 \mathrm{~mm}$ ) did not cause sand to move around the piles located at $s_{b}=500 \mathrm{~mm}$. The initial frame movement $w_{\mathrm{f}}$ (denoted by $w_{\mathrm{i}}$ hereafter) of $37 \mathrm{~mm}$ caused trivial response for each of the four test piles. An effective frame movement should be $w_{\mathrm{f}}-w_{\mathrm{i}}(\mathrm{mm})$.

- As the $w_{\mathrm{f}}$ increases from 37 to $80 \mathrm{~mm}\left(R_{\mathrm{L}}=0.17 \sim 0.29\right)$, the $M_{\max }$ for all tests increases proportionally, irrespective of the axial loads; perhaps a triangular soil movement profile prevailed for the $w_{\mathrm{f}}$. At higher $w_{\mathrm{f}}(>80 \sim 90 \mathrm{~mm})$, the $M_{\max }$ maintains a constant value and conforms to a trapezoidal soil movement.

- When $w_{\mathrm{f}}=37 \sim 80 \mathrm{~mm}$, the $M_{\max }$ in tests with the axial load (e.g., TS32-294 and TS50-294) exhibits a "delayed" increase in stiffness and attains a high ultimate value, compared with the pile without the load. (The effect is more pronounced for the deep sliding case, as shown subsequently.) A $60 \%$ increase in the $M_{\max }$ owing to the axial load for the $32 \mathrm{~mm}$ diameter piles is noted compared with $30 \%$ for the $50 \mathrm{~mm}$ diameter piles.

The $w_{\mathrm{i}}$ captures the impact of the evolution of strain wedges carried by the loading block. For instance, at $w_{\mathrm{f}}=$ $30 \mathrm{~mm}, L_{\mathrm{m}}=105 \mathrm{~mm}$, the lateral extent (at the surface) of the wedge is calculated as $225 \mathrm{~mm}\left(=105 \tan \left(45^{\circ}+40^{\circ} / 2\right)\right.$, the frictional angle of $40^{\circ}$ is used to account for the compaction effect associated with the moving). This extent is vindicated by the few "heaves" mentioned earlier (see Fig. 8h). The correlation between the maximum shear force $T_{\max }$ and $M_{\max }$ is discussed later.

\section{Response at deepest sliding depth}

Figures 14 and 15 provide the response profiles obtained using the deepest pre-selected sliding depth of $350 \mathrm{~mm}$ and the triangular loading block (TD32-0 and TD32-294). Without the axial load, the $32 \mathrm{~mm}$ diameter pile rotated principally about the middle pile embedment and the $y_{\mathrm{t}}$ reached $46 \mathrm{~mm}$ at $w_{\mathrm{f}}=110 \mathrm{~mm}$. Imposing the axial load of $294 \mathrm{~N}$ (TD32-294), the same size pile translated and rotated around the pile tip and the $y_{\mathrm{t}}$ reached $62.5 \mathrm{~mm}$. The moment and shear force profiles for the $32 \mathrm{~mm}$ piles at the maximum state $\left(w_{\mathrm{f}}=120 \mathrm{~mm}\right)$ are depicted in Figs. $16 a$ and $16 \mathrm{~b}$, respectively, together with those for $d=50 \mathrm{~mm}$. The evolution of the maximum bending moments and shear forces with the advance of the frames is illustrated in Figs. $17 a$ and $17 \mathrm{~b}$. These figures show the following features:

- The reaction from the $50 \mathrm{~mm}$ piles is negligible within a $w_{\mathrm{i}}$ of $30 \mathrm{~mm}$, which is less than $37 \mathrm{~mm}$ for $d=32 \mathrm{~mm}$ piles.

- The axial load causes constant bending moments down to a depth of $200 \mathrm{~mm}$ (Fig. 16), below which the moment distribution resembles the one from TS tests (Fig. 12) and it causes the $M_{\max }$ increase to $\sim 143 \mathrm{kN} \cdot \mathrm{mm}$ (see Fig. 16) that occurs at a depth $d_{\max }$ of $0.465 \mathrm{~m}$.

- The thrust $T_{\max }$ and the $M_{\max }$ in the pile will in general attain higher values than those seen in Figs. 14-17, as the movement $w_{\mathrm{f}}$ of $120 \mathrm{~mm}$ just mobilizes a sliding depth $L_{\mathrm{m}}$ of $350 \mathrm{~mm}$ (see Table 2).

\section{Effect of progressive moving sand on $M_{\max }$}

The evolution of $M_{\max }$ with the normalized sliding depth $R_{\mathrm{L}}$ is given in Fig. $18 a$. It shows three distinct stages: $(i)$ a small value of $M_{\max }$ at $0 \leq w_{\mathrm{f}}<37 \mathrm{~mm}\left(R_{\mathrm{L}}<0.17\right)$; (ii) the linear increase in $M_{\max }$ owing to the triangular movement profile with $37 \leq w_{\mathrm{f}}<60 \mathrm{~mm}\left(L_{\mathrm{m}}=200 \mathrm{~mm}, R_{\mathrm{L}}=0.29\right)$ or with $37 \leq w_{\mathrm{f}}<120 \mathrm{~mm}\left(L_{\mathrm{m}}=350 \mathrm{~mm}, R_{\mathrm{L}}=0.5\right)$; and (iii) the moment increases at either $R_{\mathrm{L}}=0.29$ or 0.5 that are caused by uniform movement beyond the triangular movement. The moment increases were determined by conducting four more tests on the piles $(d=32 \mathrm{~mm})$ to the pre-selected final sliding depths of $125,250,300$, and $350 \mathrm{~mm}\left(R_{\mathrm{L}}=\right.$ 
Fig. 8. Progressively moving sand induced by a triangular loading block: $w_{\mathrm{f}}=(a) 10 \mathrm{~mm} ;(b) 20 \mathrm{~mm} ;(c) 30 \mathrm{~mm}$; (d) $50 \mathrm{~mm} ;(e) 70 \mathrm{~mm}$; (f) $110 \mathrm{~mm}$; $(g) 140 \mathrm{~mm}$. (h) Overview of sand heaves at $w_{\mathrm{f}}=150 \mathrm{~mm}$.

(a)

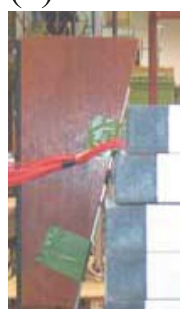

(b)

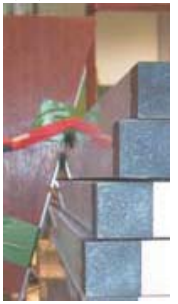

(c)

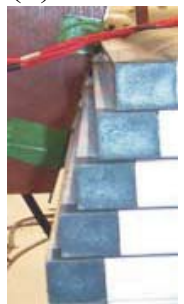

(d)

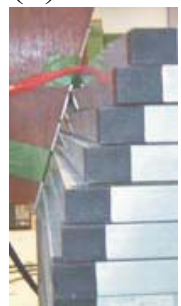

(e)

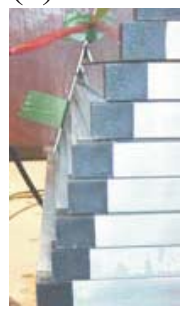

(f)

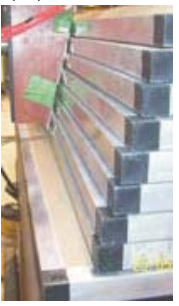

(g)

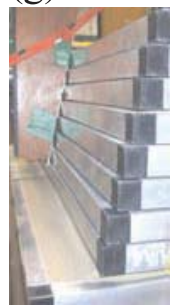

(h)

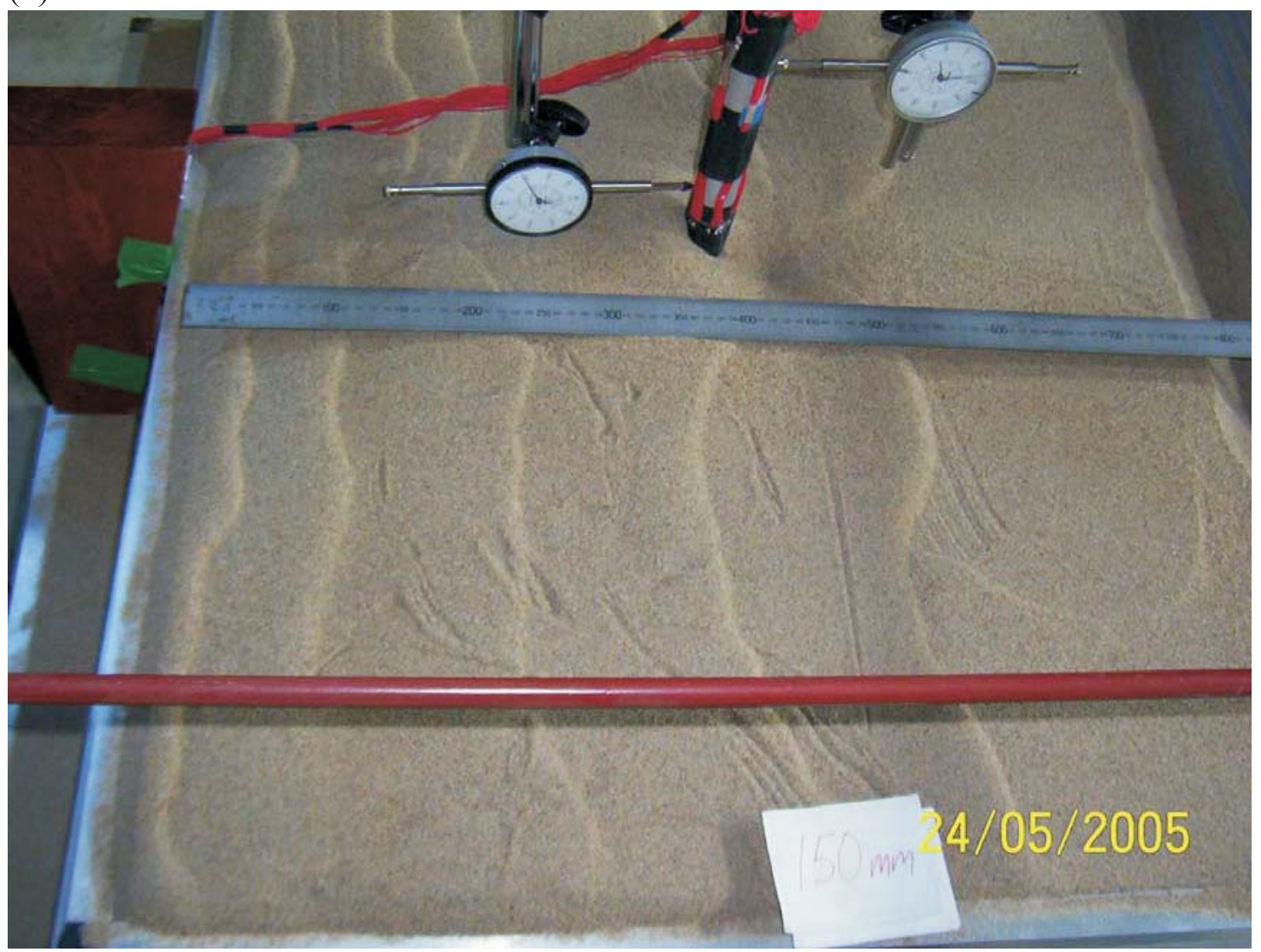

$0.179,0.357,0.429$, and 0.5 , respectively) without axial load. The magnitudes of $M_{\max }$ obtained were 5.2, 62.6, 115.3 , and $118.1 \mathrm{kN} \cdot \mathrm{mm}$ upon initiating the trapezoidal profile (see Table 2). They finally reached 5.7, 123.5, 175.0, and 140.0 (not yet to limit) $\mathrm{kN} \cdot \mathrm{mm}$, respectively. These values are plotted against $R_{\mathrm{L}}$, together with the TS32-0 test, in Fig. $18 b$. The $M_{\max }$ along with $d_{\max }, T_{\max }$, and $y_{\mathrm{t}}$ are provided in Table 1 . Note that $M_{\max }$ and $T_{\max }$ from T32-0 $\left(L_{\mathrm{m}}=350 \mathrm{~mm}\right)$ at $w_{\mathrm{f}}=120 \mathrm{~mm}$ are $1.2 \%$ and $\sim 5 \%$ less than those from TD32-0, showing the repeatability and accuracy of the current tests.

\section{Simple solutions}

Relationship between $M_{\max }$ and $T_{\max }$

Guo demonstrated that analytical solutions for laterally loaded (active) piles can be employed to study passive piles subjected to soil movement, for which the lateral load $P$ is taken as the maximum sliding force, $T_{\max }$, induced in a pile. ${ }^{2,3}$ This use with particular reference to rigid piles is further corroborated using the measured correlation between $M_{\max }$ and $T_{\max }$ and between the effective $y_{\mathrm{o}}\left(=w_{\mathrm{f}}-w_{\mathrm{i}}\right)$ and $T_{\max }$.

\section{Solutions for active rigid piles}

Given a free-head, floating-base, laterally-loaded pile, elastic solutions offer (Scott 1981)

$$
\begin{aligned}
& M_{\max }=(0.148 \sim 0.26) P L \\
& d_{\max }=(0.33 \sim 0.42) L
\end{aligned}
$$

where $P$ is the lateral load applied at the pile head level and

\footnotetext{
${ }^{3}$ Guo, W.D. A pragmatic approach for rigid passive piles in sand. Submitted for publication.
} 
Fig. 9. Variation of maximum shear force versus lateral force on loading block.

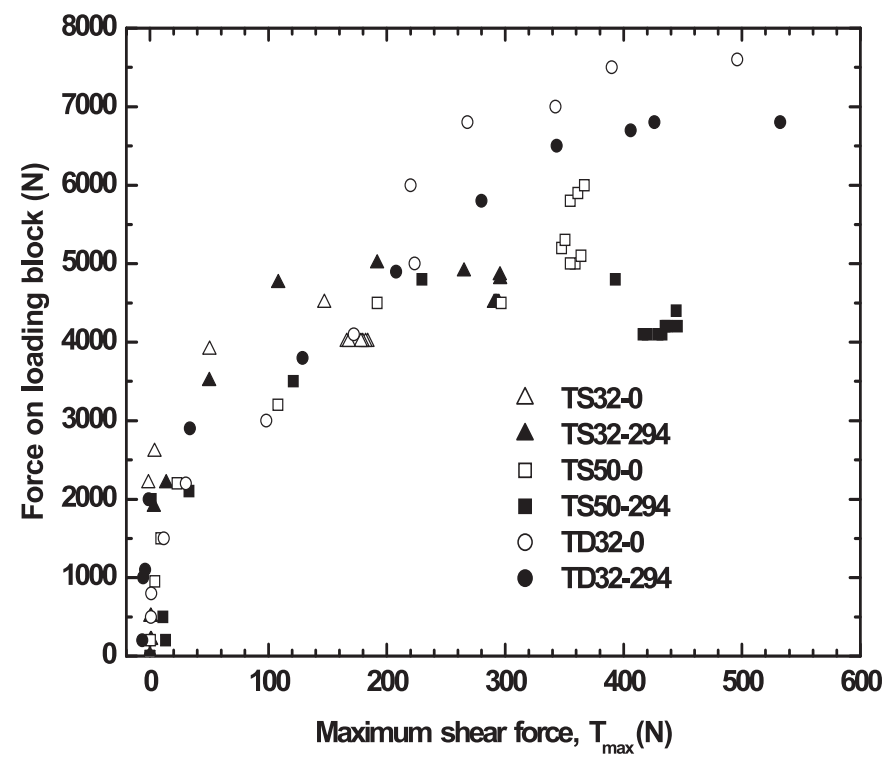

Table 2. Frame movement $\left(w_{\mathrm{f}}\right)$ versus depth of moving soil $\left(L_{\mathrm{m}}\right)$.

\begin{tabular}{lccl}
\hline $\begin{array}{l}\text { Frame } \\
\text { movement, } \\
w_{\mathrm{f}}(\mathrm{mm})\end{array}$ & $\begin{array}{l}\text { Number of } \\
\text { fully mobilized } \\
\text { frames }\end{array}$ & $\begin{array}{l}\text { Depth of soil } \\
\text { movement, } L_{\mathrm{m}} \\
(\mathrm{mm})\end{array}$ & $\begin{array}{l}\text { Sliding } \\
\text { depth } \\
\text { ratio, } R_{\mathrm{L}}\end{array}$ \\
\hline $\begin{array}{l}\text { Triangular } \\
10\end{array}$ & 2 & $\mathbf{2 0 0} \mathbf{~ m m})$ & \\
20 & 3 & 70 & 0.07 \\
30 & 4 & 100 & 0.10 \\
50 & 6 & 150 & 0.14 \\
70 & 8 & 200 & 0.21 \\
110 & 8 & 200 & 0.29 \\
120 & 8 & 200 & 0.29 \\
Triangular & profile (final $\left.\boldsymbol{L}_{\mathbf{m}}=\mathbf{3 5 0} \mathbf{~ m m}\right)$ & 0.29 \\
60 & 8 & 200 & \\
70 & 9 & 225 & 0.29 \\
80 & 10 & 250 & 0.32 \\
90 & 11 & 275 & 0.36 \\
100 & 12 & 300 & 0.39 \\
110 & 13 & 325 & 0.43 \\
120 & 14 & 350 & 0.46 \\
\hline
\end{tabular}

$d_{\max }$ is the depth of maximum bending moment. The coefficient of 0.33 or 0.148 is used for a uniform $k$, whereas 0.42 or 0.26 is for a Gibson $k$ (Scott 1981). For the pile, elasticplastic solutions provide the following correlation (Guo 2008):

[2] $\quad M_{\max }=\left(\frac{2}{3} d_{\max }+e\right) P$

where $e$ is the real or fictitious free-length of the lateral load above the ground surface. Equation [2] is of identical form to that developed for laterally loaded piles at the ultimate state (Broms 1964).

\section{Use of equivalent load for passive piles}

Equations [1] and [2] are used for passive piles by replac-
Fig. 10. Response of pile during TS32-0 with respect to $(a)$ bending moment; $(b)$ shear force; (c) deflection.
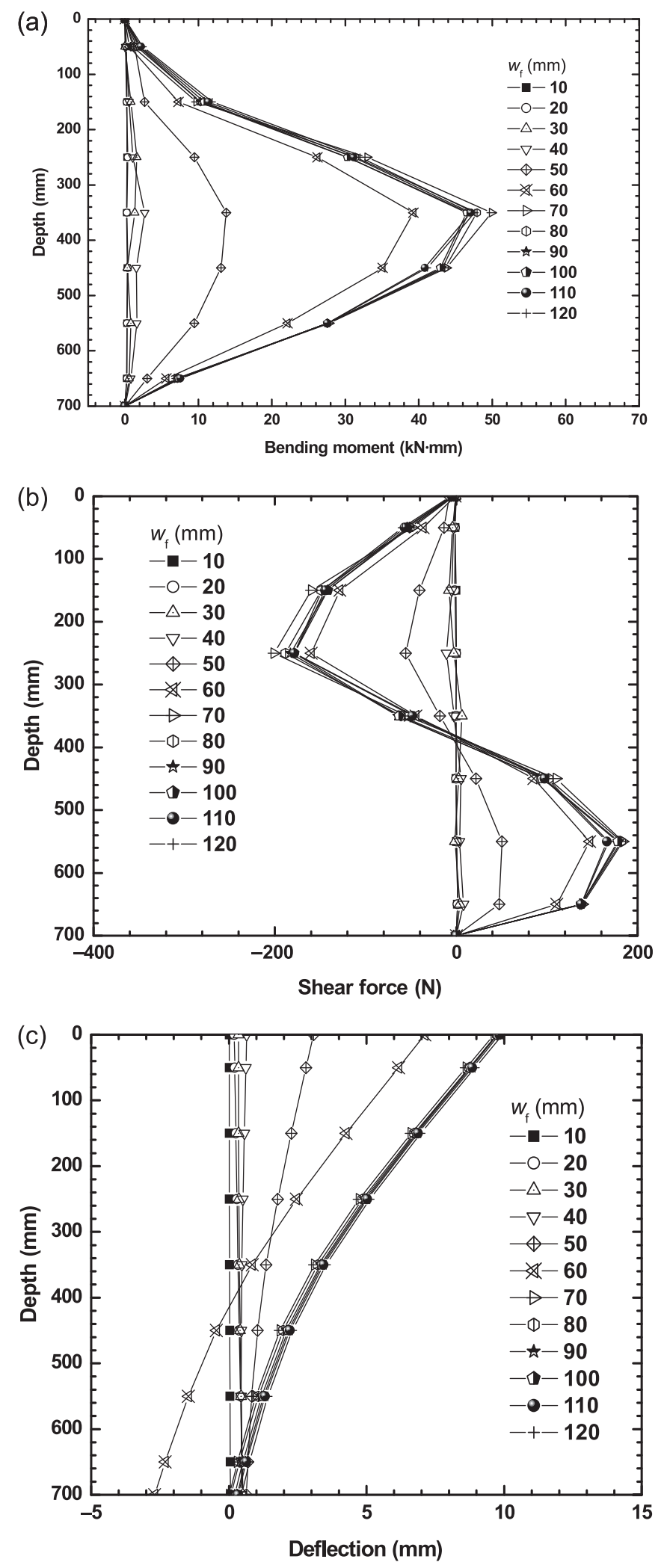

ing load $P$ with $T_{\max }$. This is justified from the following two new experimental outcomes, in addition to the similarity of on-pile force profiles between passive and active loading 
Fig. 11. Response of pile during TS32-294 with respect to (a) bending moment; (b) shear force; $(c)$ deflection.
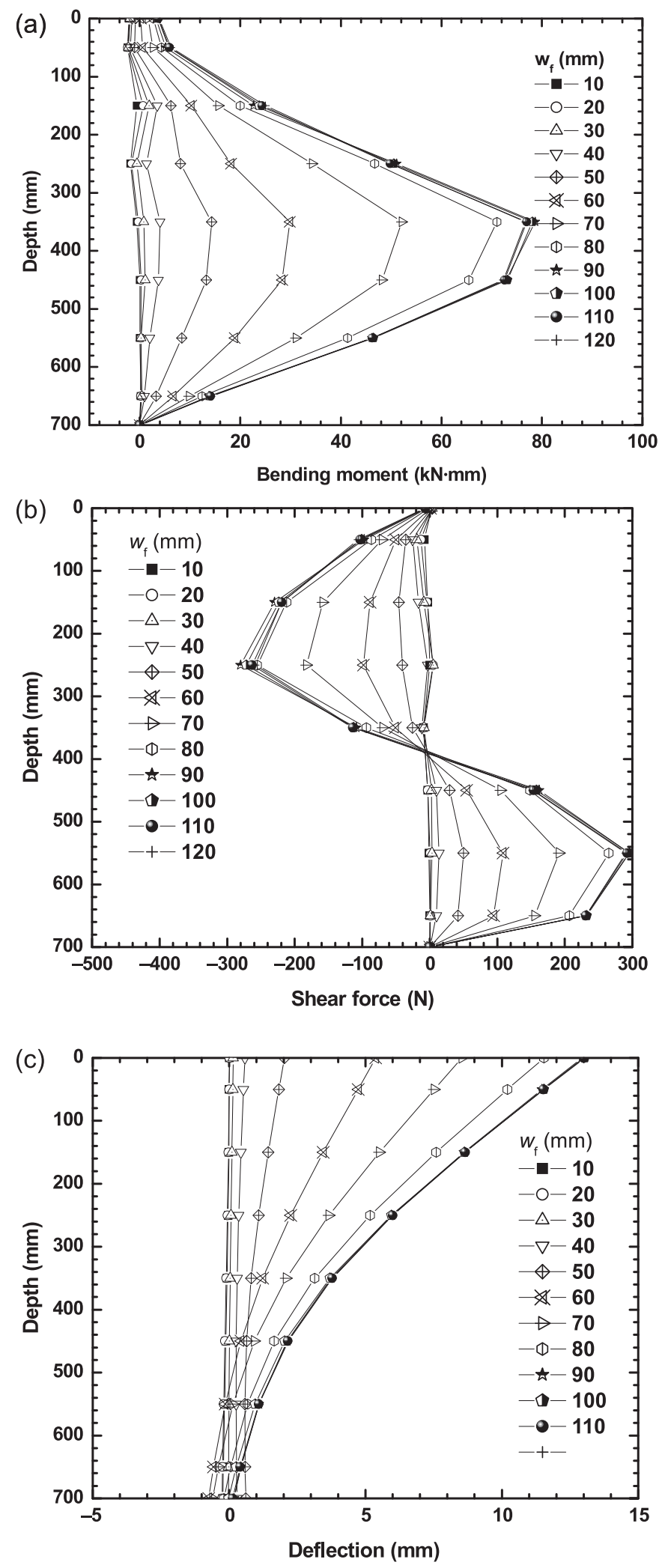

revealed previously (Guo 2003; see footnote 3 (footnote 2 in Web version)):

(1) The bending moment profile for the passive piles (see
Fig. 12. Maximum response profiles of piles (final sliding depth = $200 \mathrm{~mm}$ ): (a) bending moment profiles (measured); $(b)$ shear force profiles (measured). Data for TS50-0 and TS50-294 from Guo and Qin (2006).
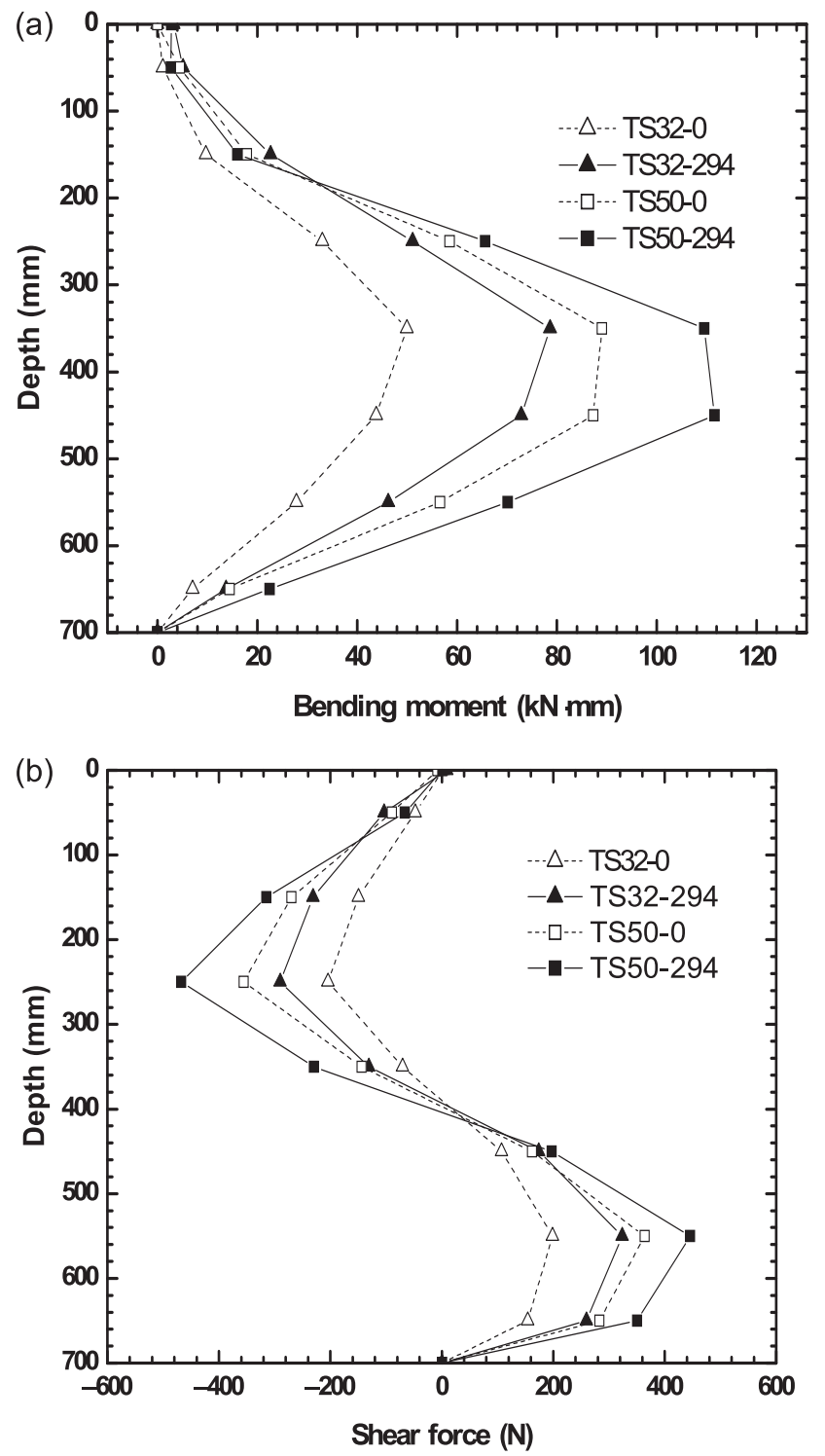

Figs. $12 a$ and $16 a$ ) shows that $d_{\max }=0.35 \sim 0.4 \mathrm{~m}$ or $(0.5 \sim 0.6) L$, such that $M_{\max }=(0.33 \sim 0.4) L T_{\max }$.

(2) The correlation between $T_{\max }$ and $M_{\max }$ is observed as linear for all the current model tests, as is demonstrated in Figs. $19 a$ and $19 b$, and for almost all the $w_{\mathrm{f}}$. Using $P=T_{\max }$ in eq. [2] to fit the measured data in Figs. $19 a$ and $19 b$ allows $M_{\max }=0.357 T_{\max } L$ to be realized.

Points (1) and (2) indicate an elastic-plastic pile-soil interaction for the current model piles and eq. [1] can be rewritten as

[3] $\quad M_{\max }=(0.148 \sim 0.4) T_{\max } L$

Equivalent elastic solutions for passive piles

The current model tests on passive piles support the following hypotheses: 
Fig. 13. Evolution of maximum response of piles (final sliding depth $=200 \mathrm{~mm}):(a)$ measured $M_{\max } ;(b)$ measured $T_{\max }$. Equi., equivalent; $k$, modulus of subgrade reaction; $y_{0}$, effective frame movement.
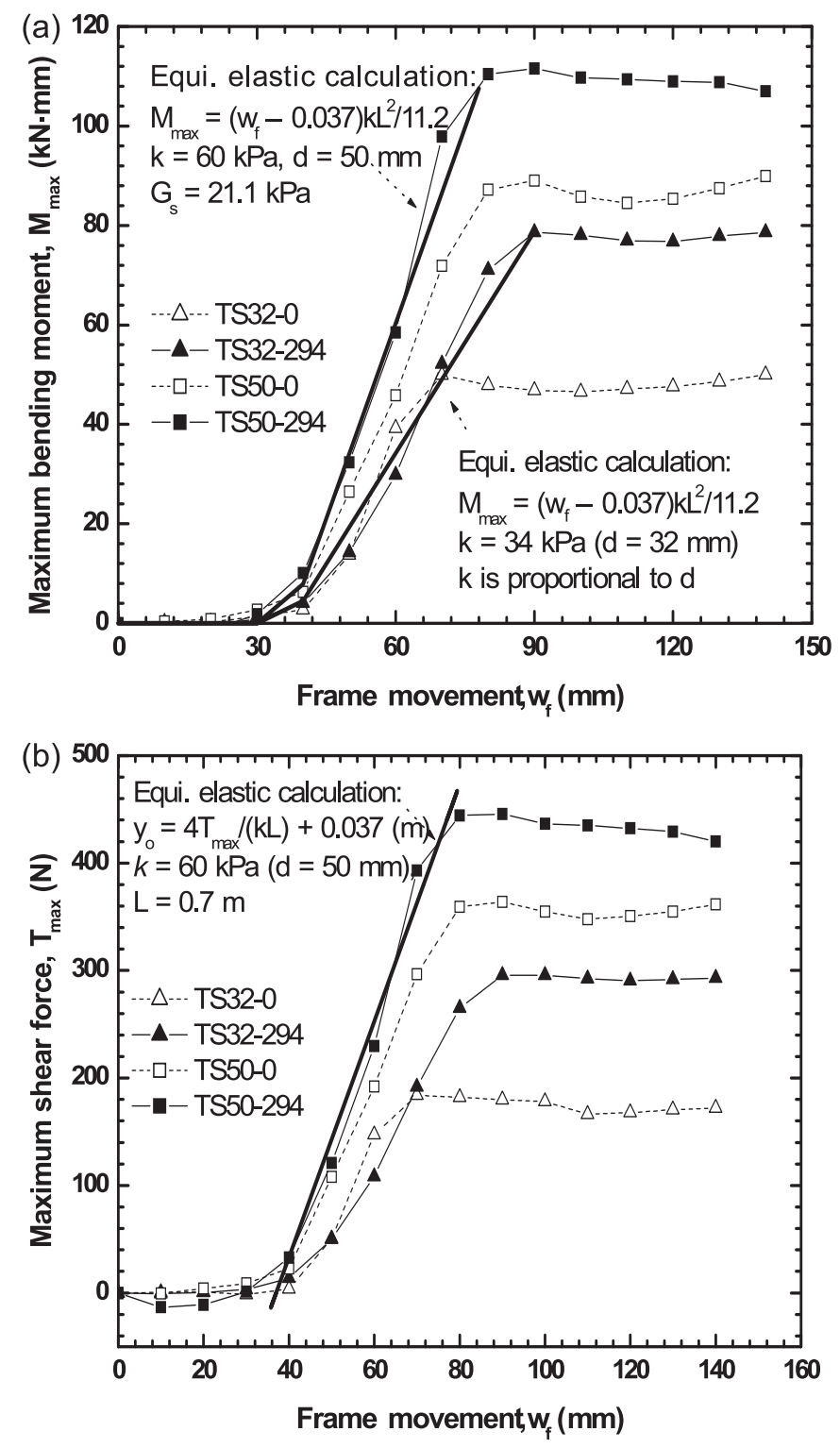

- The distance between the pile and the loading block $s_{\mathrm{b}}$ renders a significant portion of the initial frame movement $w_{\mathrm{i}}$ of $30 \sim 37 \mathrm{~mm}$ to cause a rather small reaction in the pile.

- The effective frame movement of $w_{\mathrm{f}}-w_{\mathrm{i}}\left(=y_{0}\right)$ causes the groundline deflection, $y_{t}$, during the passive loading process. Any pile-soil relative rigid movement is incorporated into the $w_{\mathrm{i}}$ and the modulus of subgrade reaction, $k$. The $y_{0}$ may be grossly estimated by using elastic theory for a lateral pile in a homogenous soil

$$
\text { [4] } y_{0}=4 T_{\max } /(k L)
$$

where $k=(2.4 \sim 3) G_{\mathrm{s}}$ (Guo 2008a). The $k$ here is proportional to pile diameter, $d$, as is noted in later calculations.

These observations offer
Fig. 14. Response of pile during TD32-0 with respect to (a) bending moment; (b) shear force; (c) deflection.
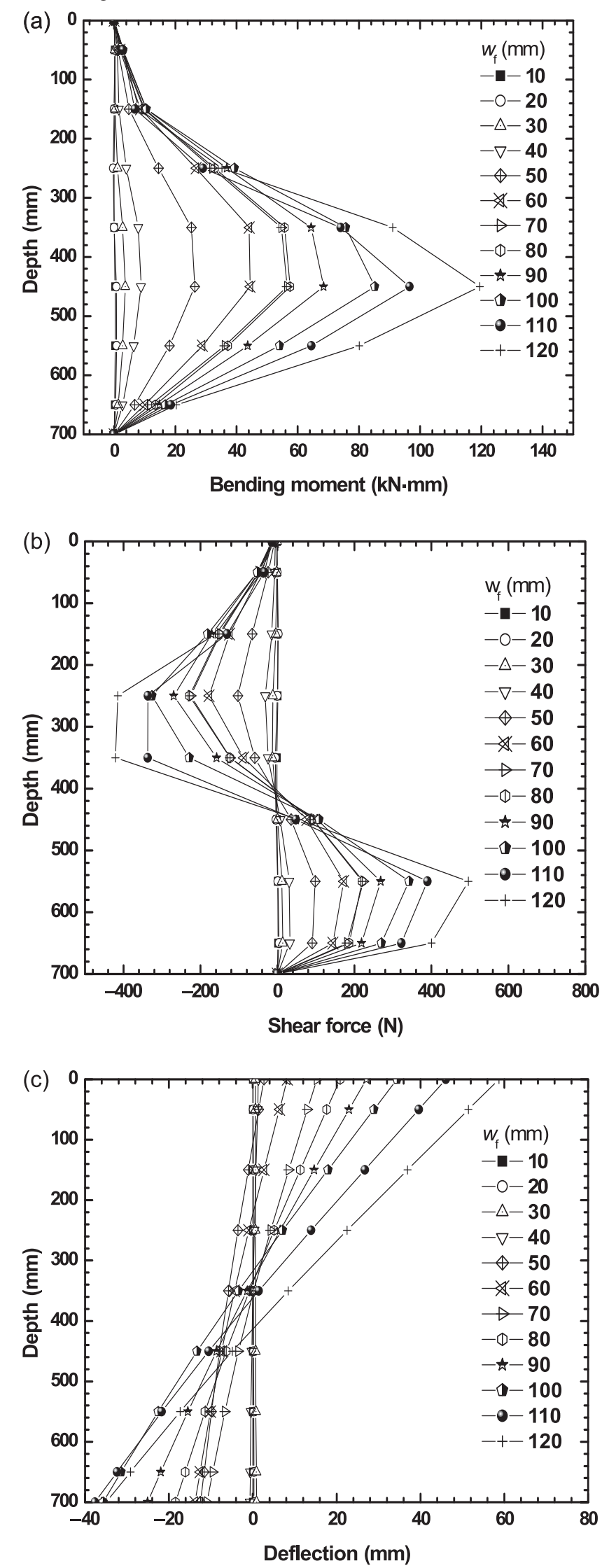

Published by NRC Research Press 
Fig. 15. Response of pile during TD32-294 with respect to (a) bending moment; (b) shear force; (c) deflection.
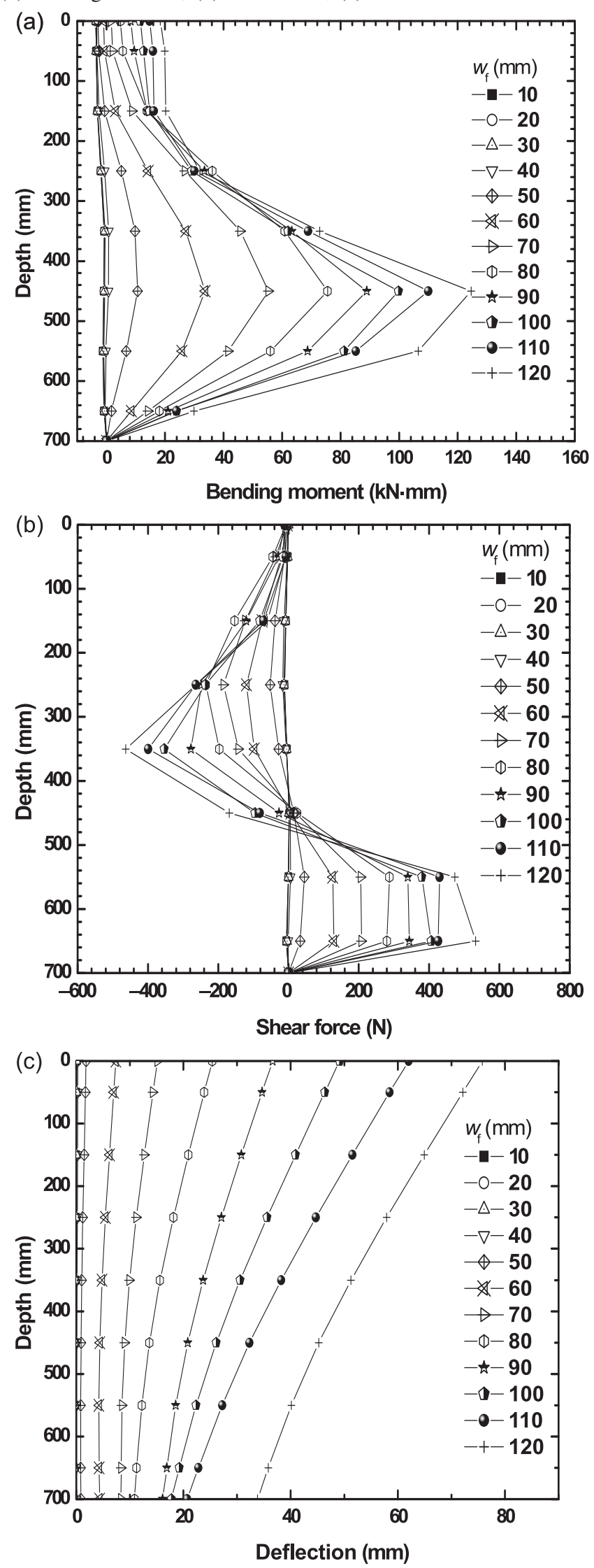

Fig. 16. Maximum response profiles of piles (final sliding depth = $350 \mathrm{~mm}$ ): (a) bending moment profiles (measured); $(b)$ shear force profiles (measured).
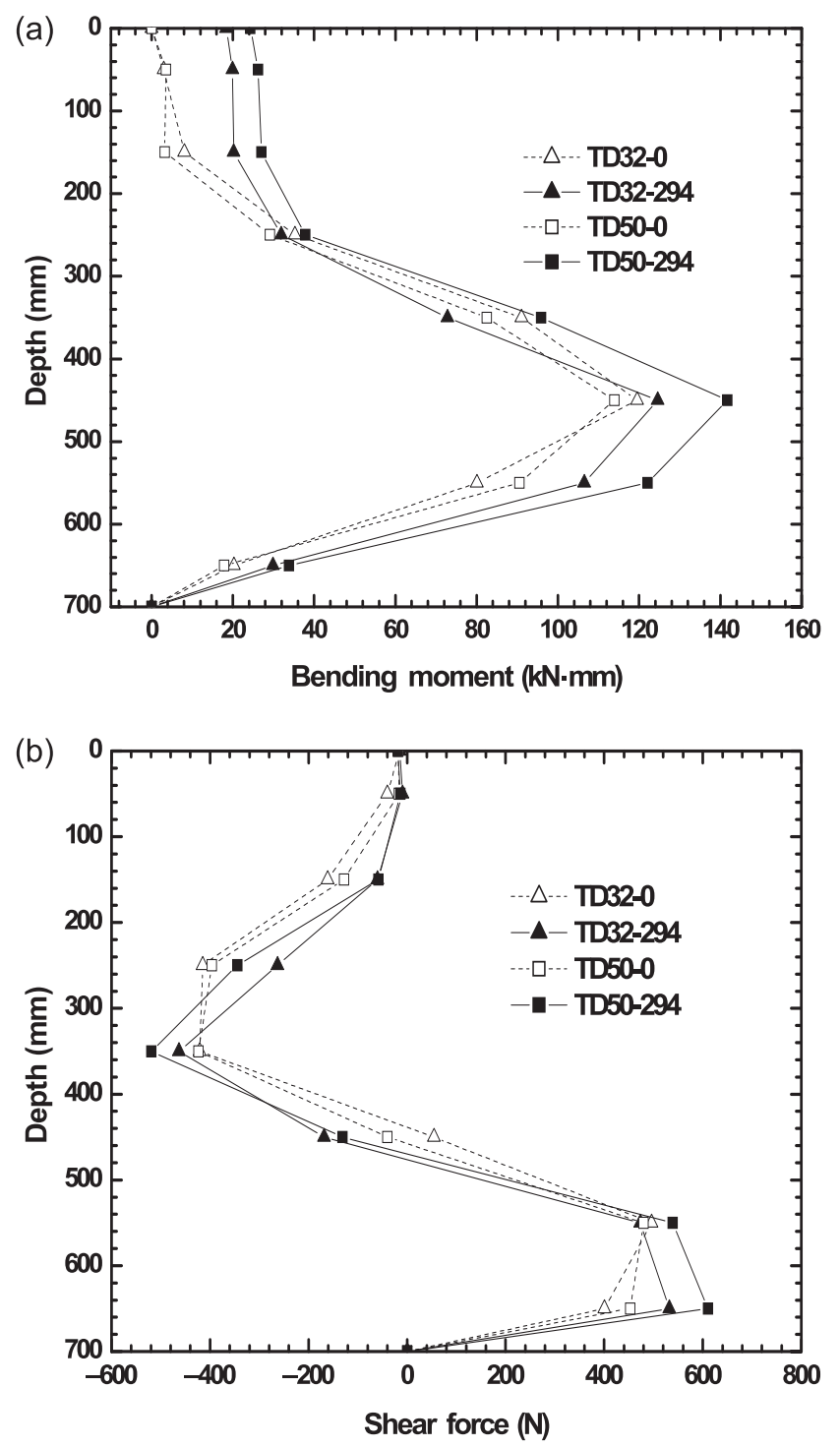

[5] $\quad T_{\max }=\left(w_{\mathrm{f}}-w_{\mathrm{i}}\right) k L / 4$

and eq. [3] may be rewritten as

[6] $\quad M_{\max }=\left(w_{\mathrm{f}}-w_{\mathrm{i}}\right) k L^{2} /(10 \sim 27)$

where $w_{\mathrm{i}}$ is the initial frame movement that depends on $s_{\mathrm{b}}$, the pile diameter, and the loading manner. For instance, $w_{\mathrm{i}}=0.03 \sim 0.037 \mathrm{~m}$ (the current translational tests) and $w_{\mathrm{i}}=$ 0.0 for the rotational tests reported by Poulos et al. (1995). The value of $15.38 \sim 27$ corresponds to the elastic case of the Gibson $k \sim$ constant $k$, whereas a value of 11.2 or 10 is adopted for the case shown in Fig. 19 and the rotating tests shown in Fig. 18b, respectively. Hereafter in this paper, all "elastic calculation" is based on a value of 15.38 (Gibson $k$ ) unless specified otherwise. The length $L$ for each pile was taken as the smallest values of $L_{i}$ (pile embedment in $i$ th layer, $i=1,2$ for sliding and stable layer, respectively, in this paper) and the equivalent length of the rigid pile, $L_{\mathrm{ci}}$. For model tests, as the sliding layer is not evident around a 
Fig. 17. Evolution of maximum response of piles (final sliding depth $=350 \mathrm{~mm})$ : $(a)$ measured $M_{\max } ;(b)$ measured $T_{\max }$.
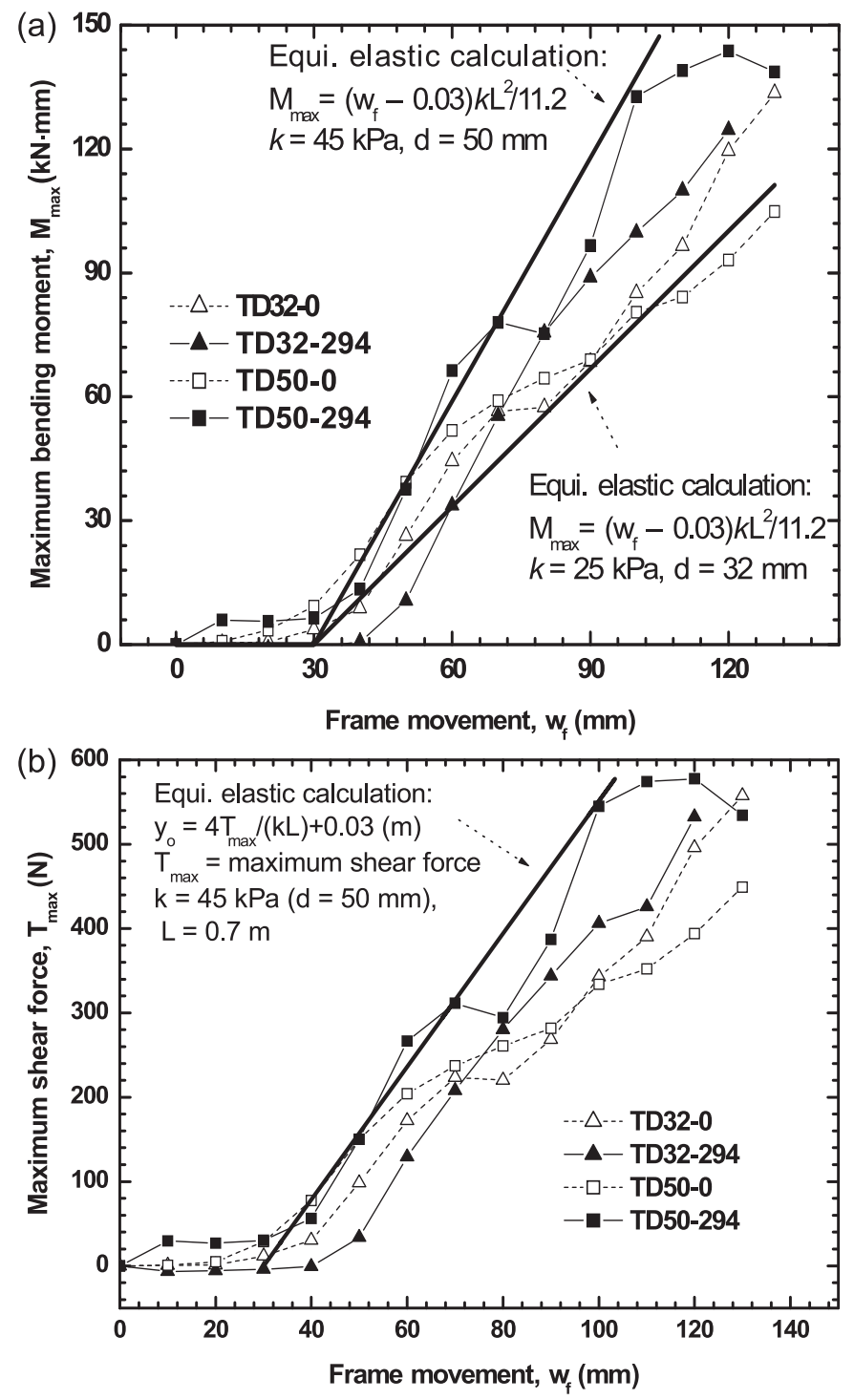

test pile, the length $L$ has to be taken as the pile embedment length. The $L_{\mathrm{ci}}$ is given by (Guo and Lee 2001)

$$
\text { [7] } \quad L_{\mathrm{ci}}=1.05 d\left(E_{\mathrm{p}} / \bar{G}_{\mathrm{s}}\right)^{0.25}
$$

where $E_{\mathrm{p}}$ is the Young's modulus of an equivalent solid cylinder pile and $\bar{G}_{\mathrm{s}}$ is the average shear modulus of soil over the depth of the $i$ th layer. When using these expressions, it must be stressed that

- The modulus $k$ is deduced from the overall sliding process characterized by the sand pile-shear box interaction. This should not be adopted for predicting the pile deflection at groundline, $y_{\mathrm{t}}$, and for the values provided in Table 1 that reflect a local pile-soil interaction. ${ }^{3} \mathrm{~A}$ higher modulus $k$ is generally seen for predicting $y_{\mathrm{t}}$ rather than the $k$ for overall sliding, especially for a local pile-soil interaction (shallow sliding depth). The pile deflection, $y_{\mathrm{t}}$, in the overall sliding process does encompass a significant component of "rigid" rotation, although in the local interaction it does not. Two local interaction cases are as
Fig. 18. Variation of maximum bending moment versus sliding depth ratio. Measured $M_{\max }$ for (a) $L_{\mathrm{m}}=200$ and $350 \mathrm{~mm}$ and (b) various sliding depths.
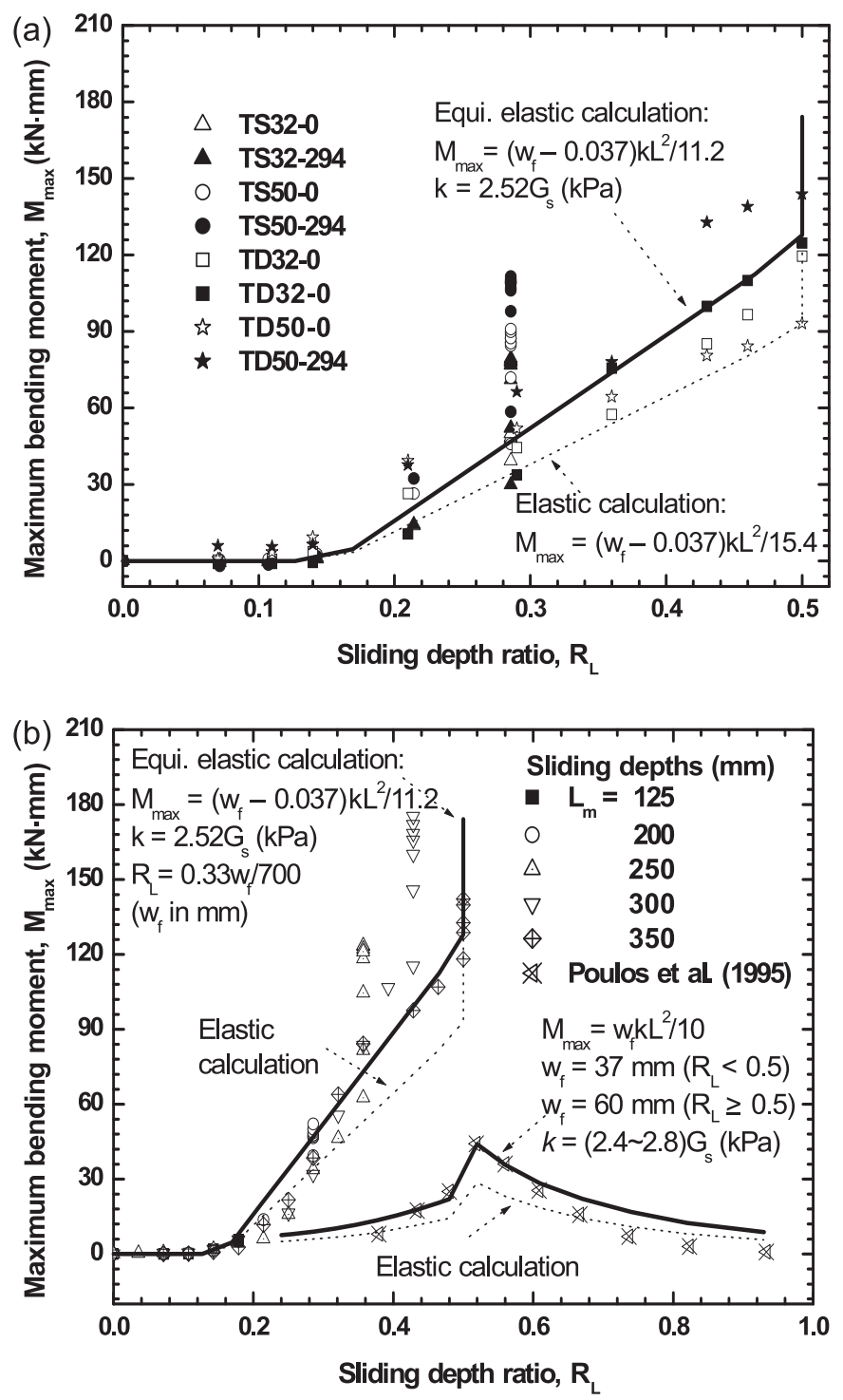

follows. ( $i)$ The deflection at groundline $y_{\mathrm{t}}$ was measured as $46 \mathrm{~mm}$ for TD32-0 under $w_{\mathrm{f}}=110 \mathrm{~mm}$. Given the measured $T_{\max }=0.4 \mathrm{kN}, k=50 \mathrm{kPa}$, and $L=0.7 \mathrm{~m}$, eq. [4] yielded a similar deflection $y_{0}$ of $45.7 \mathrm{~mm}$. (ii) The $y_{0}$ at $w_{\mathrm{f}}=110 \mathrm{~mm}$ was evaluated as $63.5 \mathrm{~mm}$ for TD32-294, in light of the measured $T_{\max }=0.5 \mathrm{kN}$, $k=45 \mathrm{kPa}$, and $L=0.7 \mathrm{~m}$, which also compares well with the measured $y_{\mathrm{t}}$ of $62.5 \mathrm{~mm}$. As expected, the values of $k$ used here are higher than $25 \sim 30 \mathrm{kPa}$ (explained later) adopted for the overall interaction illustrated in Fig. $17 b$.

- The estimated $T_{\max }$ and $M_{\max }$ must be capped by those deduced for the ultimate state. ${ }^{3}$

Example calculations of $\boldsymbol{M}_{\max }$

The current tests were conducted by translational movement of the loading block that has a loading angle of $16.7^{\circ}$. The sliding depth increases with the movement. The pre- 
Fig. 19. Maximum shear force versus maximum bending moment. Measured data for $(a) L_{\mathrm{m}}=200$ and $350 \mathrm{~mm}$ and $(b)$ various $L_{\mathrm{m}}$, $d=32 \mathrm{~mm}$.
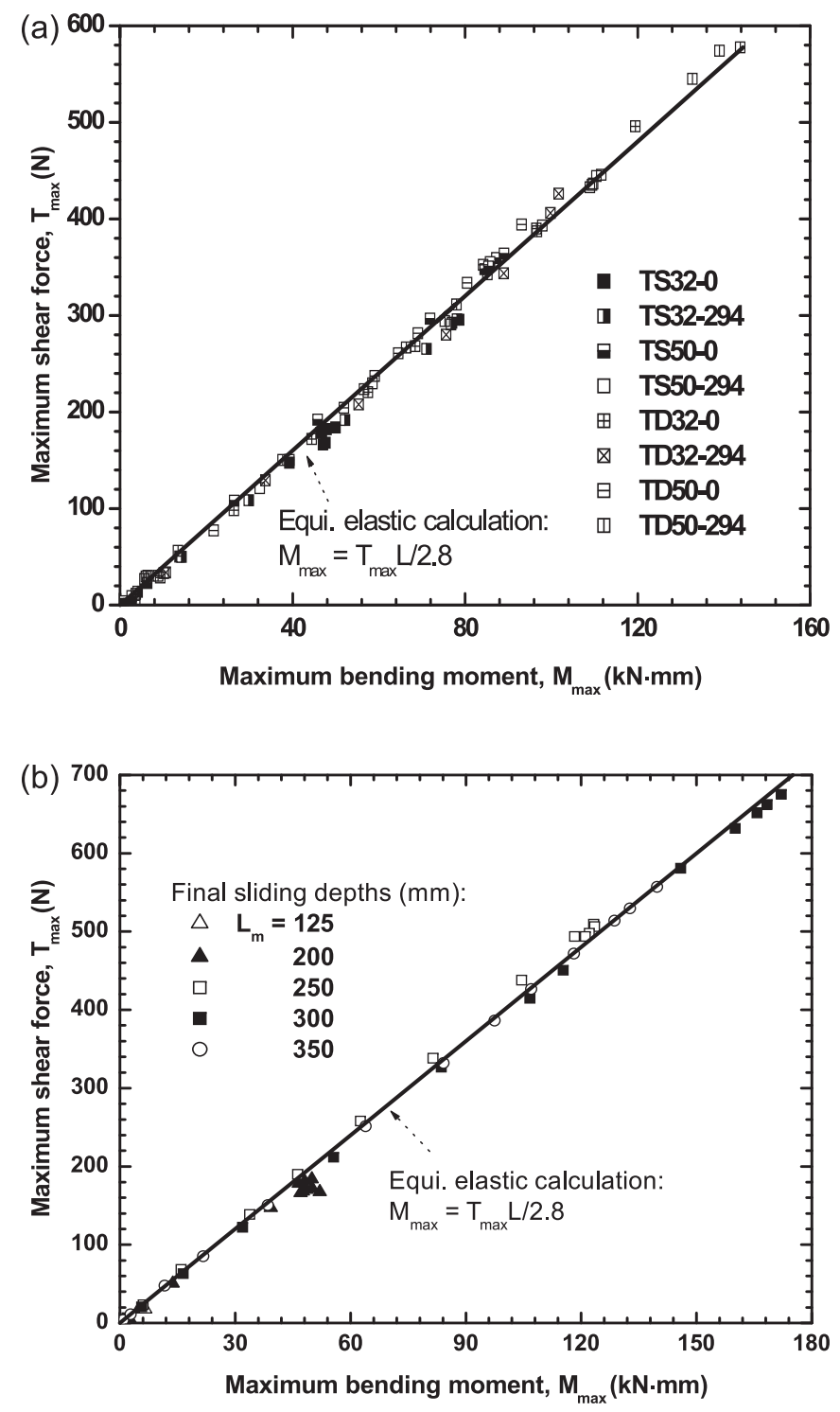

vious model pile tests (Poulos et al. 1995) were carried out by rotating a loading block (rotational loading) about a constant sliding depth for each test. The current tests were generally associated with an effective soil movement, $y_{0}$, of $30 \sim 70 \mathrm{~mm}\left(=w_{\mathrm{f}}-37(\mathrm{~mm})\right.$ in Table 3$)$, similar to the movement of $37 \mathrm{~mm}\left(R_{\mathrm{L}}<0.5\right)$ or $60 \mathrm{~mm}\left(R_{\mathrm{L}}>0.5\right)$ enforced previously (Poulos et al. 1995). Nevertheless, Fig. 18 shows a $3 \sim 5$ times difference in the magnitudes of the measured bending moment, $M_{\max }$, between the current and the previous tests. This difference and (or) impact is investigated here from three aspects using eqs. [5] and [6].

\section{TS tests, TD tests, and $k$}

The measured curves of $M_{\max } \sim w_{\mathrm{f}}$ and $T_{\max } \sim w_{\mathrm{f}}$ (see Figs. 13 and 17) were simulated regarding the pre-specified final sliding depths of $200 \mathrm{~mm}$ (TS tests) and $350 \mathrm{~mm}$ (TD tests), respectively. Elastic theory offers (Guo 2008a) $k / G_{\mathrm{s}}=$ $2.841(d=50 \mathrm{~mm})$ and $2.516(d=32 \mathrm{~mm})$. The $G_{\mathrm{s}}$ was de- duced previously as $15 \sim 21 \mathrm{kPa}$, thus the $k$ was obtained as $45 \sim 60 \mathrm{kPa}(d=50 \mathrm{~mm})$. Given $w_{\mathrm{i}}=30 \mathrm{~mm}$ (TD50-294) and $37 \mathrm{~mm}$ (TS50-294), the moment is thus calculated using $M_{\max }=\left(w_{\mathrm{f}}-w_{\mathrm{i}}\right) k L^{2} / 11.2$. They agree well with the measured data shown in the figures. As the diameter is changed to $32 \mathrm{~mm}$, the $k$ reduces to $25 \sim 35 \mathrm{kPa}$, in view of its proportional reduction to the diameter (resulting in $28.8 \sim 38.4 \mathrm{kPa}$ ), and further to the ratio of $2.516 / 2.841$. This reduced $k$ offers good estimations for the $d=32 \mathrm{~mm}$ tests as well, as shown in the figures. Equations [4]-[6] are thus sufficiently accurate for the deep and shallow sliding cases.

\section{Translational loading with variable sliding depths (constant L)}

The measured $M_{\max }$ of the piles TD32-0 and T32-0 $\left(L_{\mathrm{m}}=\right.$ 350 , Table 1) tested to a final sliding depth of $350 \mathrm{~mm}$ is presented in Table 3. It is modeled using $M_{\max }=\left(w_{\mathrm{f}}-\right.$ $0.037) k L^{2} / 11.2$ and $k=35 \mathrm{kPa}$. The estimated $M_{\max }$ for a series of $w_{\mathrm{f}}$ (or $R_{\mathrm{L}}$ ) are also provided in Table 3 and plotted in Fig. 18a. The $R_{\mathrm{L}}$ was based on actual observation during the tests, which may be slightly different from the calculated one using $R_{\mathrm{L}}=0.33 w_{\mathrm{f}} / L$. The same calculation is also plotted in Fig. $18 b$. The moment increase at $R_{\mathrm{L}}=0.5$ (for $w_{\mathrm{f}}>$ $120 \mathrm{~mm}$ ) was especially estimated using an additional movement of $30 \mathrm{~mm}$ beyond the $w_{\mathrm{f}}$ of $120 \mathrm{~mm}$ to show the (capped) ultimate value. ${ }^{3}$ Table 3 shows that the calculated value agrees with the two sets of measured $M_{\text {max }}$, in view of using the same $w_{\mathrm{i}}$ of $37 \mathrm{~mm}$ for either test.

\section{Rotational loading about a fixed sliding depth}

The $M_{\max }$ was obtained in model pile tests by loading with rotation about a fixed sliding depth (thus, a typical $R_{\mathrm{L}}$ ) (Poulos et al. 1995). The results for a series of $R_{\mathrm{L}}$ were depicted in Fig. $18 b$ and are tabulated in Table 4. This measured $M_{\max }$ is simulated via the following steps:

- The ratio of $k / G_{\mathrm{s}}$ was obtained as $2.39 \sim 2.79$ using the closed-form expression by Guo and Lee (2001), which itself is a function of a factor $\gamma(=1.05 \mathrm{~d} / \mathrm{L})$.

- Shear modulus was stipulated as $G_{\mathrm{s}}=10 z\left(G_{\mathrm{s}}\right.$ in $\mathrm{kPa}, z=$ $L_{\mathrm{s}}+L_{\mathrm{m}}$ in $\mathrm{m}$ ), from which the $k$ was thus calculated.

- With $w_{\mathrm{i}}=0$ (as observed), the $T_{\max }$ was estimated using eq. [5] for $w_{\mathrm{f}}=37 \mathrm{~mm}\left(R_{\mathrm{L}}<0.5\right)$ or $w_{\mathrm{f}}=60 \mathrm{~mm}\left(R_{\mathrm{L}}>\right.$ $0.5)$.

- The $M_{\max }$ was calculated as $M_{\max }=w_{\mathrm{f}} k L^{2} / 10$ as per eq. [6].

The test piles were of lengths $375 \sim 675 \mathrm{~mm}$, and the $G_{\mathrm{s}}$ was $3.75 \sim 6.75 \mathrm{kPa}$. The values of the $M_{\max }$ calculated for the 10 model piles are provided in Table 4 . They are plotted against the ratio $R_{\mathrm{L}}$ in Fig. $18 b$, which serves well as an upper bound of all the measured data.

Overall, eqs. [5] and [6] offer good estimations of $M_{\max }$ (thus, $T_{\max }$ ) for all the current 12 model piles (e.g., Table 3) and the previous 10 tests (e.g., Table 4 ). The $3 \sim 5$ times difference in the $M_{\max }$ is likely owing to the dominant impact of the pile dimensions (via $L$ and the ratio $k / G_{\mathrm{s}}$ ), the subgrade modulus $k$, the effective movement $\left(w_{\mathrm{f}}-\mathrm{w}_{\mathrm{i}}\right)$, and the loading manner $\left(w_{\mathrm{i}}\right)$.

\section{Calibration against in situ test piles}

The simple correlations proposed here are validated using 
Table 3. Calculation for translating pile test TD32-0 and T32-0 $\left(L_{\mathrm{m}}=350 \mathrm{~mm}\right)$.

\begin{tabular}{|c|c|c|c|c|c|c|}
\hline \multicolumn{3}{|c|}{ Input data } & \multicolumn{2}{|c|}{ Calculated $^{a}$} & \multicolumn{2}{|c|}{ Measured $M_{\max }(\mathrm{kN} \cdot \mathrm{mm})$} \\
\hline$w_{\mathrm{f}}(\mathrm{mm})$ & $G_{\mathrm{s}}(\mathrm{kPa})$ & $R_{\mathrm{L}}$ & $T_{\max }(\mathrm{kN})$ & $M_{\max }(\mathrm{kN} \cdot \mathrm{mm})$ & $\mathrm{T} 32-0$ & TD32-0 \\
\hline 30 & 14 & 0.1270 & 0 & 0 & 0.86 & 3.66 \\
\hline 40 & 14 & 0.1693 & 0.018 & 4.62 & 2.78 & 8.80 \\
\hline 50 & 14 & 0.2116 & 0.080 & 20.04 & 11.68 & 26.37 \\
\hline 60 & 14 & 0.2540 & 0.142 & 35.45 & 21.69 & 44.42 \\
\hline 70 & 14 & 0.2963 & 0.203 & 50.86 & 38.47 & 56.56 \\
\hline 80 & 14 & 0.3386 & 0.265 & 66.27 & 63.96 & 57.50 \\
\hline 90 & 14 & 0.3809 & 0.327 & 81.68 & 84.23 & 68.40 \\
\hline 100 & 14 & 0.4233 & 0.388 & 97.09 & 97.51 & 85.17 \\
\hline 110 & 14 & 0.4656 & 0.450 & 112.50 & 106.98 & 96.56 \\
\hline 120 & 14 & 0.6398 & 0.512 & 127.92 & 118.12 & 119.50 \\
\hline $150^{b}$ & 14 & 0.7997 & 0.697 & 174.15 & 139.78 & - \\
\hline
\end{tabular}

Table 4. Calculation for rotating tests (Poulos et al. 1995).

\begin{tabular}{|c|c|c|c|c|c|c|c|c|}
\hline \multicolumn{4}{|l|}{ Input data } & \multicolumn{4}{|l|}{ Calculated } & \multirow[b]{2}{*}{$\begin{array}{l}\text { Measured } \\
M_{\max } \\
(\mathrm{kN} \cdot \mathrm{mm})\end{array}$} \\
\hline $\begin{array}{l}\text { Embedded } \\
\text { length } L(\mathrm{~mm})\end{array}$ & $w_{\mathrm{f}}(\mathrm{mm})$ & $G_{\mathrm{s}}(\mathrm{kPa})$ & $R_{\mathrm{L}}$ & $\begin{array}{l}\text { Factor } \gamma \\
(=1.05 \mathrm{~d} / \mathrm{L})\end{array}$ & $k / G_{\mathrm{s}}$ & $T_{\max }(\mathrm{kN})$ & $\begin{array}{l}M_{\max } \\
(\mathrm{kN} \cdot \mathrm{mm})\end{array}$ & \\
\hline 525 & 37 & 5.25 & 0.38 & 0.05000 & 2.54 & 0.0648 & 13.62 & 8.0 \\
\hline 575 & 37 & 5.75 & 0.43 & 0.04565 & 2.48 & 0.0760 & 17.47 & 17.4 \\
\hline 625 & 37 & 6.25 & 0.48 & 0.04200 & 2.43 & 0.0879 & 21.97 & 25.0 \\
\hline 675 & 60 & 6.75 & 0.52 & 0.03889 & 2.39 & 0.1631 & 44.03 & 44.2 \\
\hline 625 & 60 & 6.25 & 0.56 & 0.04200 & 2.43 & 0.1425 & 35.63 & 36.1 \\
\hline 575 & 60 & 5.75 & 0.61 & 0.04565 & 2.48 & 0.1232 & 28.33 & 25.5 \\
\hline 525 & 60 & 5.25 & 0.67 & 0.05000 & 2.54 & 0.1051 & 22.08 & 15.8 \\
\hline 475 & 60 & 4.75 & 0.74 & 0.05526 & 2.61 & 0.0884 & 16.79 & 7.1 \\
\hline 425 & 60 & 4.25 & 0.82 & 0.06176 & 2.69 & 0.0729 & 12.39 & 3.0 \\
\hline 375 & 60 & 3.75 & 0.93 & 0.07000 & 2.79 & 0.0588 & 8.82 & 0.8 \\
\hline
\end{tabular}

the measured response of eight in situ test piles and one centrifuge test pile subjected to soil movement. The pile and soil properties are tabulated in Table 5, along with the measured values of the maximum bending moment $M_{\max }$. The shear force, $T_{\max }$, however, was measured for three of the nine piles. The $T_{\max }$ for the remaining six piles was thus taken as that deduced using elastic and elastic-plastic theory (Cai and Ugai 2003; see footnote 2 (footnote 1 in Web version)). The modulus of the subgrade reaction, $k_{\mathrm{i}}$, and the equivalent length of the rigid pile, $L_{\mathrm{ci}}$, were calculated previously. ${ }^{2}$ The length $L$ for each pile was taken as the smallest values of $L_{\mathrm{i}}$ and $L_{\mathrm{ci}}$. This allows the ratio $M_{\max } /\left(T_{\max } L\right)$ for each case to be evaluated. The results are tabulated in Table 5 and are plotted in Fig. 20. The ratios all fall into the range of the elastic solutions based on a constant $k$ for the plastic solution of eq. [3]. The slightly higher ratio for the exceptional Katamachi-B is anticipated. ${ }^{2}$ It may be argueed that four piles with a ratio of $0.26-0.4$ exhibit elastic-plastic pile-soil interaction, with an eccentricity greater than zero.

Figure 19 shows that the ratio $M_{\max } /\left(T_{\max } L\right)$ from model pile tests stays almost invariably at 0.357 from the initial to ultimate loading state. The same ratio for the in situ pile (Frank and Pouget 2008) was calculated for the sliding and stable layers, respectively, with respect to the "pre-pull back" (behaving as free head) and "after pull back" (fixed head) situation for the 16 years' test duration. This ratio is plotted in Fig. 21. The ratio for the pile in the sliding layer stays around 0.25 . (Note that the ratio for the stable layer as plotted in Fig. 21 seems to be complicated, but it is beyond the scope of this paper.) In brief, the ratio $M_{\max } /\left(T_{\max } L\right)$ is independent of loading level for either the model tests or the field test.

Determination of the $T_{\max }$ is, however, more pertinent to pile head or base constraints. A fully fixed head observes $y_{\mathrm{t}}=T_{\max } /(k L)$ (Guo and Lee 2001) and a semi-fixed head follows $y_{\mathrm{t}}=(1 \sim 4) T_{\max } /(k L)$.

- The in situ pile (Frank and Pouget 2008) for the pre-pull back situation is evaluated using the free head solution. The $k$ was obtained as $8.8 \mathrm{MPa}\left(=100 s_{\mathrm{u}}\right.$, where undrained shear strength $s_{\mathrm{u}}=88 \mathrm{kPa}$ ). At a groundline deflection $y_{\mathrm{t}}=32 \mathrm{~mm}$ (recorded on 5 July 1995), the $T_{\max }$ was estimated as $478.7 \mathrm{kN}\left(=y_{\mathrm{t}} \mathrm{kL} / 4\right)$. This $T_{\max }$ agrees well with the measured load of $487 \mathrm{kN}$. Note that the measured pile deflection increases approximately linearly from groundline to a depth of $6.8 \sim 8.0 \mathrm{~m}$, exhibiting "rigid" characteristics.

- The calculation of deflection and bending moment for rigid piles is illustrated in light of the two-row piles used to stabilize a sliding slope (Kalteziotis et al. 1993). Each 
Table 5. $M_{\max } /\left(T_{\max } L\right)$ determined for field tests.

\begin{tabular}{|c|c|c|c|c|c|c|c|c|}
\hline \multicolumn{3}{|l|}{ Piles } & \multicolumn{2}{|l|}{ Soil } & \multicolumn{2}{|c|}{ Measured } & \multirow[b]{2}{*}{$\begin{array}{l}M_{\max } / \\
\left(T_{\max } L\right)^{b}\end{array}$} & \multirow[b]{2}{*}{ References } \\
\hline $\begin{array}{l}D / t^{a} \\
(\mathrm{~mm})\end{array}$ & $\begin{array}{l}E_{\mathrm{p}}{ }^{a} \\
(\mathrm{GPa})\end{array}$ & $\begin{array}{l}L_{1} / L_{2}^{a} \\
(\mathrm{~m})\end{array}$ & $\begin{array}{l}k_{1} / k_{2}^{a} \\
(\mathrm{MPa})\end{array}$ & $\begin{array}{l}L_{\mathrm{c1}} / L_{\mathrm{c} 2}{ }^{a} \\
(\mathrm{~m})\end{array}$ & $\begin{array}{l}M_{\max }{ }^{a, b} \\
(\mathrm{kNm})\end{array}$ & $\begin{array}{l}T_{\max }^{a} \\
(\mathrm{kN})\end{array}$ & & \\
\hline $790 / 395$ & 20 & $7.5 / 22.5$ & $8.0 / 8.0$ & $19.5 / 19.5$ & 903 & 310 & 0.388 & Esu and D'Elia (1974) \\
\hline $1200 / 600$ & 20 & $9.5 / 13.0$ & $15 / 15$ & $12.7 / 12.7$ & 2250 & 600 & 0.395 & Carrubba et al. (1989) \\
\hline $630 / 315$ & 28.45 & $2.5 / 10.0$ & $14.4 / 28.8$ & $23.1 / 23.1$ & 60.2 & $56-60^{c}$ & $0.40-0.43$ & Leung et al. (2000) $(2.5 \mathrm{~m})$ \\
\hline $630 / 315$ & 28.45 & $3.5 / 9.0$ & $14.4 / 28.8$ & $23.1 / 23.1$ & 73.8 & $65-85^{c}$ & $0.25-0.32$ & Leung et al. (2000) $(3.5 \mathrm{~m})$ \\
\hline $630 / 315$ & 28.45 & $4.5 / 8.0$ & $14.4 / 28.8$ & $23.1 / 23.1$ & 81.2 & $72-100^{c}$ & $0.18-0.25$ & Leung et al. (2000) $(4.5 \mathrm{~m})$ \\
\hline $318.5 / 6.9$ & 210 & $11.2 / 12.8$ & $5.0 / 8.0$ & $6.3 / 5.6$ & 165.2 & $144-150^{c}$ & $0.18-0.20$ & Hataori- $2^{d}$ \\
\hline $318.5 / 6.9$ & 210 & $8.0 / 9.0$ & $5.0 / 15.0$ & $6.3 / 4.9$ & 65.7 & $70-71.2^{c}$ & $0.15-0.19$ & Hataori- $3^{d}$ \\
\hline $318.5 / 6.9$ & 210 & $6.5 / 7.5$ & $5.0 / 8.0$ & $6.3 / 5.6$ & 197.2 & $143-300^{c}$ & $0.10-0.25$ & Kamimoku- $4^{d}$ \\
\hline $318.5 / 6.9$ & 210 & $4.0 / 6.0$ & $5.0 / 8.0$ & $6.3 / 5.6$ & 290.3 & $231-250^{c}$ & $0.18-0.22$ & Kamimoku- $6^{d}$ \\
\hline $300 / 60$ & 20 & $7.3 / 5.7$ & $6.0 / 10.0$ & $3.2 / 2.8$ & 69.5 & $40-56.2^{c}$ & $0.38-0.62$ & Katamachi-B ${ }^{d}$ \\
\hline $915 / 19$ & $31.1^{e}$ & $6.8 / 4.2$ & $8.8 / 8.8$ & $9.7 / 9.7$ & $901.9^{f}$ & $532.6^{f}$ & $0.249^{f}$ & 5 November $1986^{g}$ \\
\hline & & & & & $312.5^{f}$ & $221.9^{f}$ & $0.207^{f}$ & 4 November $1986^{g}$ \\
\hline & & & & & $1102.3^{f}$ & $642.3^{f}$ & $0.252^{f}$ & 11 November $1988^{g}$ \\
\hline & & & & & $536.6^{f}$ & $369.5^{f}$ & $0.214^{f}$ & 10 November $1988^{g}$ \\
\hline & & & & & $1473.5^{f}$ & $796.4^{f}$ & $0.272^{f}$ & 1 October $1992^{g}$ \\
\hline & & & & & $544.3^{f}$ & $378.5^{f}$ & $0.211^{f}$ & 30 September $1992^{g}$ \\
\hline & & & & & $1434.2^{f}$ & $834.7^{f}$ & $0.253^{f}$ & 6 July $1995^{g}$ \\
\hline & & & & & $756.1^{f}$ & $487.0^{f}$ & $0.228^{f}$ & 5 July $1995^{g}$ \\
\hline
\end{tabular}

${ }^{a}$ See footnote 2 (footnote 1 in Web version); $D$, outside diameter; $t$, wall thickness; $E_{\mathrm{p}}$, Young's modulus of pile; $L_{1} / L_{2}$, thickness of sliding/stable layer; $k_{1} / k_{2}$ , subgrade modulus of sliding/stable layer; $L_{\mathrm{c} 1} / L_{\mathrm{c} 2}$, equivalent length for rigid pile in sliding/stable layer. In the estimation, $G_{\mathrm{s} i}$ was simply taken as $k_{i} / 3$.

${ }^{b} M_{\max }$ is the measured maximum bending moment; $L$ is the the smallest value of $L_{\mathrm{i}}$ and $L_{\mathrm{ci}}$.

${ }^{c}$ Estimated using elastic and elastic-plastic solutions versus measured bending moment and pile deflection and soil movement profiles .

${ }^{d}$ Cai and Ugai (2003).

${ }^{e}$ Flexural stiffness $E_{\mathrm{p}} I_{\mathrm{p}}=1070 \mathrm{MN} \cdot \mathrm{m}^{2}$.

${ }^{f}$ All for sliding layer.

${ }^{g}$ Frank and Pouget (2008). Date shown refers to date that indicated values were recorded.

Fig. 20. Calculated versus measured ratios of $M_{\max } /\left(T_{\max } L\right)$.

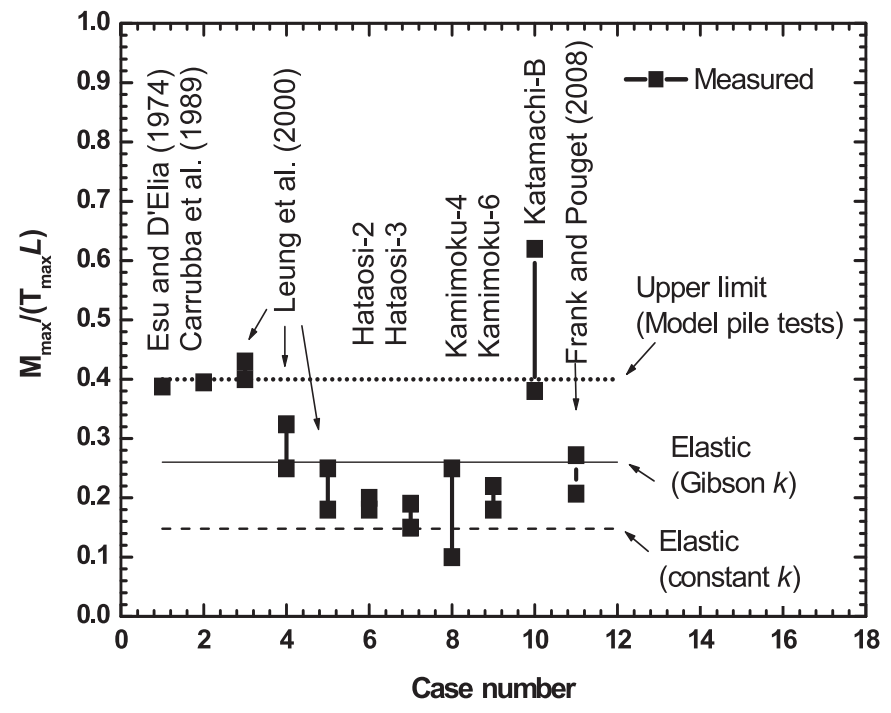

steel pile had a length of $12 \mathrm{~m}$, an external diameter of $1.03 \mathrm{~m}$, a wall thickness, $t$, of $18 \mathrm{~mm}$, and a flexural stiffness, $E_{\mathrm{p}} I_{\mathrm{p}}$, of $1540 \mathrm{MN} \cdot \mathrm{m}^{2}$. Given $k=k_{1}=15 \mathrm{MPa}$ (Chen and Poulos 1997) and an equivalent rigid pile length $L=L_{1}=4 \mathrm{~m}$ (sliding depth), it follows that $T_{\max }=45 \mathrm{kN}\left(=y_{\mathrm{t}} \mathrm{kL} / 4\right)$ at $y_{\mathrm{t}}=0.003 \mathrm{~m}$. This $T_{\max }$ compares well with the measured $40 \sim 45 \mathrm{kN}$. The $T_{\max }$ gives a uniform on-pile force per unit length of 10-11.25 kN/m. The moment is thus estimated as $80 \sim 90 \mathrm{kN} \cdot \mathrm{m}$
Fig. 21. Measured $M_{\max }$ and $T_{\max }$ (data from Frank and Pouget 2008).

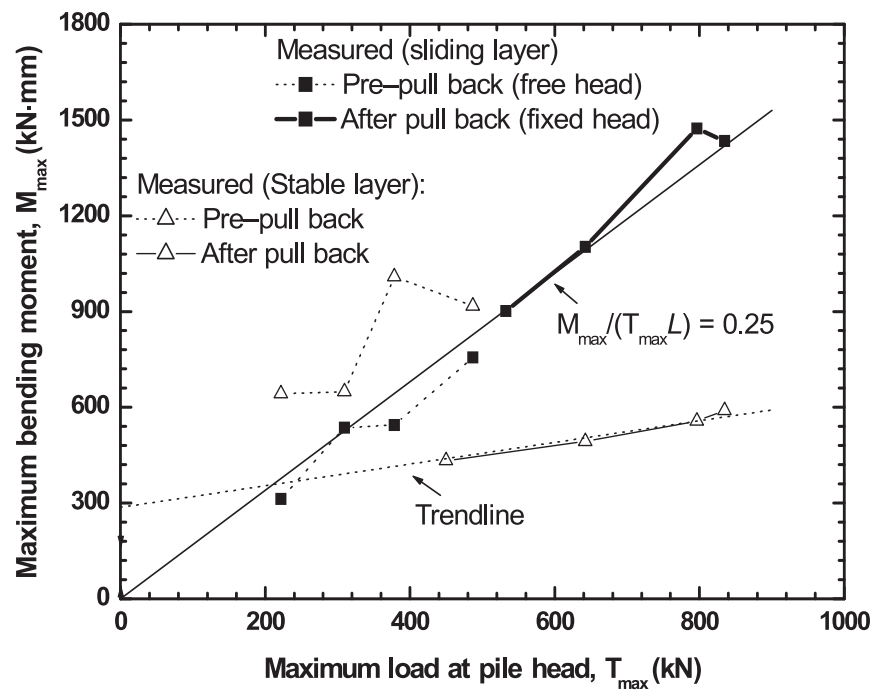

$\left(=0.5 \times(10 \sim 11.25) \times 4^{2}\right)$ about the sliding depth and as $180 \sim 202.5 \mathrm{kN} \cdot \mathrm{m}$ about the $6 \mathrm{~m}$ depth. The average moment agrees well with the measured $150 \mathrm{kN} \cdot \mathrm{m}$, considering that the depth of sliding may be 4-6 m (Chow 1996; Chen and Poulos 1997).

\section{Conclusions}

An experimental apparatus was developed to investigate 
the behaviour of vertically loaded, free head piles in sand undergoing lateral soil movement. A large number of tests have been conducted to date. Presented here are 14 typical tests concerning two diameters ( 32 and $50 \mathrm{~mm}$ ), two loading levels (0 and 294 N, 7\%-9\% of the driving force), and varying sliding depths imposed by a triangular loading block. Results are provided for the applied force, induced shear force, bending moment, and deflection along the piles. The tests enable simple solutions to be proposed for predicting the pile response.

The model tests show the following features:

- $M_{\max }$ is generally linearly related to the sliding force, $T_{\max }$, even for the initial frame movement up to $w_{\mathrm{i}}$ and the extra large $w_{\mathrm{f}}$ for the trapezoidal movement profile.

- Maximum bending moment increases by $60 \%$ for the $32 \mathrm{~mm}$ diameter piles or $30 \%$ for the $50 \mathrm{~mm}$ piles, and its depth increases by $\sim 50 \%$, upon applying a static load of 7\%-9\% of the maximum driving force.

- $3 \sim 5$ times different bending moments can occur given a similar size of model piles, but with a different loading manner.

With respect to the solutions, the following can be drawn:

- Equation [6] may be used to estimate the maximum bending moment, $M_{\max }$, for which the sliding thrust, $T_{\max }$, is calculated using eq. [5]. The estimation should adopt an effective frame movement of $w_{\mathrm{f}}-w_{\mathrm{i}}$, in which the $w_{\mathrm{i}}$ depends on the pile diameter, pile position, and loading manner.

- The subgrade modulus, $k$, may be estimated using the theoretical ratio of $k / G_{\mathrm{s}}$ and the shear modulus, $G_{\mathrm{s}}$ (e.g., $15 \sim 21 \mathrm{kPa}$ in the current tests). The $G_{\mathrm{s}}$ is pertinent to either the overall shear process of the pile-soil-shear box system or the local pile-soil interaction. The $k$ varies with diameter and should be considered accordingly.

- Based on the equivalent elastic pile-soil interaction, the $T_{\max }$ from eq. [5] must be capped by the ultimate plastic state.

The current simple solutions, although approximate, offer satisfactory estimations of the $3 \sim 5$ times different $M_{\max }$ recorded in the current and previous model pile tests, and the correct ranges of $M_{\max } /\left(T_{\max } L\right)$ for eight in situ test piles and a centrifuge test pile.

\section{Acknowledgements}

The work reported here was supported by Australian Research Council Discovery Grant (DP0209027). The financial assistance is gratefully acknowledged. The authors would like to thank Mr. Enghow Ghee for his assistance with the experiment.

\section{References}

Abdoun, T., Dobry, R., O'Rourke, T.D., and Goh, S.H. 2003. Pile response to lateral spreads: Centrifuge modeling. Journal of Geotechnical and Geoenvironmental Engineering, ASCE, 129(10): 869-878. doi:10.1061/(ASCE)1090-0241(2003) 129:10(869).

Anagnostopoulos, C., and Georgiadis, M. 1993. Interaction of axial and lateral pile responses. Journal of the Geotechnical Engineering Division, ASCE, 119(4): 793-798. doi:10.1061/(ASCE) 0733-9410(1993)119:4(793).
Aubeny, C.P., Han, S.W., and Murff, J.D. 2003. Inclined load capacity of suction caissons. International Journal for Numerical and Analytical Methods in Geomechanics, 27(14): 1235-1254. doi:10.1002/nag.319.

Bransby, M.F., and Springman, S.M. 1997. Centrifuge modelling of pile groups adjacent to surcharge loads. Soils and Foundations, 37(2): 39-49.

Broms, B. 1964. Lateral resistance of piles in cohesionless soils. Journal of the Soil Mechanics and Foundation Engineering Division, ASCE, 90(3): 123-156.

Cai, F., and Ugai, K. 2003. Response of flexible piles under laterally linear movement of the sliding layer in landslides. Canadian Geotechnical Journal, 40(1): 46-53. doi:10.1139/t02-103.

Carrubba, P., Maugeri, M., and Motta, E. 1989. Esperienze in vera grandezza sul comportamento di pali per la stabilizzaaione di un pendio. In Proceedings of the XVII Convegno Nazionale di Geotechica, Taormina, Italy, 26-28 April 1989. Associazione Geotecnica Italiana, Rome. Vol. 1, pp. 81-90. [In Italian.]

Chen, L.T., and Poulos, H.G. 1997. Piles subjected to lateral soil movements. Journal of Geotechnical and Geoenvironmental Engineering, ASCE, 123(9): 802-811. doi:10.1061/(ASCE)10900241(1997)123:9(802).

Chmoulian, A. 2004. Briefing: Analysis of piled stabilisation of landslides Proceedings of the Institution of Civil Engineers, Geotechnical Engineering, 157(2): 55-56. doi:10.1680/geng. 157.2.55.42388.

Chow, Y.K. 1996. Analysis of piles used for slope stabilization. International Journal for Numerical and Analytical Methods in Geomechanics, 20(9): 635-646. doi:10.1002/(SICI)10969853(199609)20:9<635::AID-NAG839>3.0.CO;2-X.

Esu, F., and D'Elia, B. 1974. Interazione terreno-struttura in un palo sollecitato dauna frana tipo colata. Rivista Italiana di Geotechica, 8(1): 27-38. [In Italian].

Frank, R., and Pouget, P. 2008. Experimental pile subjected to long duration thrusts owing to a moving slope. Géotechnique, 58(8): 645-658. doi:10.1680/geot.2008.58.8.645.

Fukuoka, M. 1977. The effects of horizontal loads on piles due to landslides. In Proceedings of the 9th International Conference on Soil Mechanics and Foundation Engineering, Specialty Session 10, Tokyo, 10-15 July 1977. Japanese Geotechnical Society, Tokyo. Vol. 1, pp. 27-42.

Guo, W.D. 2003. A simplified approach for piles due to soil movement. In Proceedings of the 12th Panamerican Conference on Soil Mechanics and Geotechnical Engineering, Cambridge, Mass., 22-26 June 2003. Verlag Gluckauf GMBH, Essen, Germany. Vol. 2, pp. 2215-2220.

Guo, W.D. 2008. Laterally loaded rigid piles in cohesionless soil. Canadian Geotechnical Journal, 45(5): 676-697. doi:10.1139/ T07-110.

Guo, W.D., and Ghee, E.H. 2004. Model tests on single piles in sand subjected to lateral soil movement. In Proceedings of the 18th Australasian Conference on the Mechanics of Structures and Materials, Perth, Australia, 1-3 December 2004. Edited by A.J. Deeks and H. Hao A.A. Balkema, Rotterdam, the Netherlands. Vol. 2, pp. 997-1003.

Guo, W.D., and Ghee, E.H. 2005. A preliminary investigation into the effect of axial load on piles subjected to lateral soil movement. In Proceedings of the 1st International Symposium on Frontiers in Offshore Geotechnics, Perth, Australia, 19-21 September 2005. Edited by S. Gourvenec and M. Cassidy. Taylor and Francis, London. Vol. 1, pp. 865-871.

Guo, W.D., and Lee, F.H. 2001. Load transfer approach for laterally loaded piles. International Journal for Numerical and Analy- 
tical Methods in Geomechanics, 25(11): 1101-1129. doi:10. 1002/nag.169.

Guo, W.D., and Qin, H.Y. 2006. Vertically loaded piles in sand subjected to triangular profiles of soil movements. In Proceedings of the 10th International Conference on Piling and Deep Foundations, Amsterdam, the Netherlands, 31 May - 2 June 2006. Deep Foundations Institute, Hawthorne, N.J. Vol. 1, Paper No. 1371.

Guo, W.D., Qin, H.Y., and Ghee, E.H. 2006. Effect of soil movement profiles on vertically loaded single piles. In Proceedings of the 6th International Conference on Physical Modelling in Geotechnics, Hong Kong, 4-6 August 2006. Taylor and Francis Group plc, London. Vol. 2, pp. 841-846.

Ito, T., and Matsui, T. 1975. Methods to estimate lateral force acting on stabilizing piles. Soils and Foundations, 15(4): 43-59.

Kalteziotis, N., Zervogiannis, H., Frank, R., Seve, G., and Berche, J.-C. 1993. Experimental study of landslide stabilization by large diameter piles. In Proceedings of the International Symposium on Geotechnical Engineering of Hard Soils - Soft Rocks, Athens. A. A. Balkema, Rotterdam, the Netherlands. Vol. 2, pp. 1115-1124.

Karthigeyan, S., Ramakrishna, V.V.G.S.T., and Rajagopal, K. 2007. Numerical investigation of the effect of vertical load on the lateral response of piles. Journal of Geotechnical and Geoenvironmental Engineering, 133(5): 512-521. doi:10.1061/(ASCE) 1090-0241(2007)133:5(512).

Knappett, J.A., and Madabhushi, S.P.G. 2009. Influence of axial load on lateral pile response in liquefiable soils. Part II: numerical modelling. Géotechnique, 59(7): 583-592. doi:10.1680/geot. 8.010.3750.

Leung, C.F., Chow, Y.K., and Shen, R.F. 2000. Behaviour of pile subject to excavation-induced soil movement. Journal of Geotechnical and Geoenvironmental Engineering, ASCE, 126(11): 947-954. doi:10.1061/(ASCE)1090-0241(2000)126:11(947).
Meyerhof, G.G., Mathur, S.K., and Valsangkar, A.J. 1981. Lateral resistance and deflection of rigid wall and piles in layered soils. Canadian Geotechnical Journal, 18(2): 159-170. doi:10.1139/ t81-021.

Meyerhof, G.G., Yalcin, A.S., and Mathur, S.K. 1983. Ultimate pile capacity for eccentric inclined load. Journal of the Geotechnical Engineering Division, ASCE, 109(3): 408-423. doi:10. 1061/(ASCE)0733-9410(1983)109:3(408).

Pan, J.L., Goh, A.T.C., Wong, K.S., and Teh, C.I. 2002. Ultimate soil pressure for piles subjected to lateral soil movements. Journal of Geotechnical and Geoenvironmental Engineering, ASCE, 128(6): 530-535. doi:10.1061/(ASCE)1090-0241(2002) 128:6(530).

Poulos, H.G. 1995. Design of reinforcing piles to increase slope stability. Canadian Geotechnical Journal, 32(5): 808-818. doi:10.1139/t95-078.

Poulos, H.G., Chen, L.T., and Hull, T.S. 1995. Model tests on single piles subjected to lateral soil movement. Soils and Foundations, 35(4): 85-92.

Scott, R.F. 1981. Foundation analysis. Prentice Hall, Englewood Cliffs, N.J.

Smethurst, J.A., and Powrie, W. 2007. Monitoring and analysis of the bending behaviour of discrete piles used to stabilise a railway embankment. Géotechnique, 57(8): 663-677. doi:10.1680/ geot.2007.57.8.663.

Stewart, D.P., Jewell, R.J., and Randolph, M.F. 1994. Design of piled bridge abutment on soft clay for loading from lateral soil movements. Géotechnique, 44(2): 277-296.

Viggiani, C. 1981. Ultimate lateral load on piles used to stabilise landslide. In Proceedings of the 10th International Conference on Soil Mechanics and Foundation Engineering, Stockholm, Sweden, 15-19 June 1981. A.A. Balkema, Rotterdam, the Netherlands. Vol. 3, pp. 555-560. 